\title{
Unhealthy Assimilation or Persistent Health Advantage? A Longitudinal Analysis of Immigrant Health in the United States
}

\author{
Yao Lu \\ Nicole Denier \\ Julia Shu-Huah Wang \\ Neeraj Kaushal
}

\section{Full citation:}

Lu, Yao, Nicole Denier, Julia Shu-Huah Wang, and Neeraj Kaushal. 2017. "Unhealthy Assimilation or Persistent Health Advantage? A Longitudinal Analysis of Immigrant Health in the United States.” Social Science \& Medicine 195:105-114.

\section{Corresponding author:}

Yao Lu

Department of Sociology

Columbia University

501 Knox Hall

606 W. 122nd Street

New York, NY 10027

yao.1u@columbia.edu 


\title{
Unhealthy Assimilation or Persistent Health Advantage? A Longitudinal Analysis of Immigrant Health in the United States
}

\begin{abstract}
Existing evidence on immigrant health assimilation, which is largely based on cross-sectional data, suggests that immigrants' initial health advantage erodes over time. This study uses longitudinal data to directly compare the self-rated health trajectories of immigrants and the native-born population. Data come from four panels of the Survey of Income and Program Participation (1996, 2001, 2004, and 2008), with each panel containing 2-4 years of health information. Results show that immigrants' self-rated health remained stable during the period under study, but there was a concomitant decline in health for the native-born population. This result pointed to a persistent health advantage of immigrants during the period under study. The pattern held for immigrants of different length of residence and was especially salient for those originally from Latin America and Asia. Our findings that immigrants maintain their health advantage do not support the pattern of unhealthy assimilation commonly reported in crosssectional studies.
\end{abstract}

Keywords: United States; immigrant health; unhealthy acculturation; assimilation; longitudinal data 


\section{Introduction}

A large strand of research on immigrant integration has shown that on average immigrants to the U.S. arrive with better health than the native-born population, but this initial health advantage erodes with longer residence in the U.S. (Abraído-Lanza et al. 2005; Lara et al. 2005; Rubalcava et al., 2008; Escobar et al., 2000, Singh and Miller, 2004; Cho et al., 2004; Hummer, Powers, Pullum, Gossman, \& Frisbie, 2007; Antecol and Bedard 2006; Acevedo-Garcia et al., 2010). This pattern has been demonstrated when self-rated health was the focus of investigation, with longer length of stay associated with a poorer change in health (Lara et al. 2005; Cho et al., 2004; Acevedo-Garcia et al., 2010; Finch and Vega 2003; Lee et al. 2012). As such, the health of immigrants is expected to eventually converge toward the health of the native-born population. This pattern generally holds for different immigrant groups, although recent research finds that immigrant health does not always decline monotonically over time (Teitler et al. 2012). The erosion of immigrants' initial health advantage has been explained by a process of unhealthy acculturation, such as adoption of unhealthy lifestyles and dietary practices, acculturation stress related to exposure to negative socioeconomic conditions, and environmental factors such as racial discrimination (Akresh 2007; Antecol and Bedard 2006; Cho, Frisbie, Hummer, \& Rogers, 2004; Hummer, 1996; Biddle, Kennedy, and McDonald, 2007; Finch and Vega 2003; Kaestner et al., 2009).

The available evidence largely relies on cross-sectional data, comparing the health of immigrants with different durations of stay in the host country (e.g. 0-5 years, 6-10 years, 11-20 years, $>20$ years) at a single point in time. This approach uses the duration effects as a proxy for the process of health acculturation. But in cross-sectional analysis, it potentially confounds 
duration effects with cohort of arrival effects (i.e., secular change in cohort characteristics) (Hamilton and Hummer 2011; Antecol and Bedard 2006). Indeed, the characteristics of immigrant cohorts arriving in different time periods may vary. For example, if immigrant cohorts arriving in more recent periods (and thus with shorter duration of stay in the U.S.) manifest better health on average than those who arrived in earlier periods (correspondingly longer duration of stay), cross-sectional estimates would associate better health with shorter duration of stay and point to a health deterioration, even in the absence of unhealthy acculturation. This pattern could occur owing to improving epidemiological regimes worldwide, which lead to healthier populations in sending countries over time. A few recent studies advance the literature by controlling for cohort of arrival when evaluating differences by duration of residence (Antecol and Bedard 2006; Cho et al. 2004, Hamilton and Hummer 2011). Hamilton and Hummer (2011) find that after adjusting for a rich set of factors, including cohort of arrival, the negative relationship between length of stay and health disappears for blacks. African immigrants maintained their health advantage in self-rated health over US-born blacks even after more than 20 years in the U.S. In contrast, Antecol and Bedard (2006) and Cho et al. (2004) found immigrant health deteriorated over time after controlling for cohorts of arrival.

Even after accounting for cohort of arrival, studies based on cross-sectional data may not adequately account for individual heterogeneity within and across arrival cohorts and duration groups, especially if cohorts and duration groups differ in unobserved ways (Borjas 1985). Moreover, cross-sectional studies do not directly address the key process of interest--change in health over time. Direct evidence for the deterioration of immigrants' health advantage, or unhealthy acculturation, requires two conditions. First, the health of immigrants deteriorates over 
time. Second, the health decline for immigrants is steeper than that of the native-born population. If over time immigrants' health remains stable (while the health of native born declines or remains stable), or if it declines at a similar or slower rate than the native-born population, their relative health advantage would persist. The different scenarios are illustrated in Figure 1. We included only situations of stable or declining health but not improving health, because the latter scenario is unlikely to occur due to the aging process. In the top panel, the convergence would indicate a process of unhealthy assimilation. Any pattern in the bottom panel would indicate that immigrants have maintained, if not widened, their health advantage over time. The most appropriate strategy for adjudicating which health process characterizes the experience of immigrants is through analyzing longitudinal data to document whether the health trajectories of immigrants differ from those of the native population over time.

[Figure 1 about here]

A growing number of studies exploit longitudinal data to study immigrant health trajectories (Chiswick, Lee, and Miller 2008; Kim, Carrasco, Muntaner et al. 2013; Newbold 2005; Ng et al. 2005). Most of these studies were conducted in Australia and Canada. They provide important insights but offer mixed evidence. This is partly because some of these studies focus only on changes in immigrant health and do not include the native-born population as a comparison group. The omission makes it difficult to examine how the health trajectories of immigrants compare to that of the native-born population. The longitudinal studies that compare immigrants to the native-born find a greater likelihood of health decline among immigrants in Canada (Newbold 2005; Ng et al. 2005; Setia et al. 2012). Longitudinal immigrant health 
research in the U.S. is scarce, with a notable exception. One recent study examined the self-rated health trajectories of elderly immigrants in the U.S. (Gubernskaya 2014). The study found that at age 50, immigrants reported better health than the native born. But some groups of immigrants experienced a steeper decline in health after age 50 than the native born. It remains to be seen whether adult immigrants in general manifest similar or different patterns.

The current study seeks to extend previous studies by directly comparing longitudinal health trajectories of immigrants and the native population. Our study covered a wider age spectrum (i.e., general adult population) and focused on self-rated health. We further examined whether the health trajectories vary for distinct groups of immigrants characterized by different duration of residence and region of origin to uncover potentially diverse patterns. Immigrants of different duration of residence may be likely to undergo varying degrees of socioeconomic and cultural assimilation, both carrying health implications. Also, immigrants' origin may matter, both because of possible cultural differences in interpretations of one's health and because the benefits garnered from immigration could differ, with immigrants originated from less developed regions enjoying greater economic improvement and thus more health benefits.

\section{Methods}

\subsection{Data}

The current study used longitudinal data from the Survey of Income and Program Participation (SIPP) to compare health trajectories between immigrants and the native-born population. SIPP is a nationally representative longitudinal survey of the non-institutionalized population in the United States. We used the 1996, 2001, 2004, and 2008 panels of SIPP, which cover the period 
of 1996 to 2013. The 1996 panel has four years of longitudinal data and began with a nationally representative sample of 36,730 households. The 2001, 2004, and 2008 panels have, respectively, three, four, and five years of longitudinal data, with an initial sample of 35,100, 43,500, and 42,000 households. Respondents were interviewed every four months to collect information on labor markets outcomes and program participation. Information on self-rated health was collected annually in the Medical Expenses topical modules for 4 years in the 1996 panel, 3 years in the 2001 panel, 2 years in the 2004 panel, and 3 years in the 2008 panel. Given the panel design, the data provided 2-4 years of health data, allowing us to focus on relatively short-term health trajectories. One advantage of SIPP is that it provides a relatively large sample of immigrants (allowing for disaggregation by cohorts and region of origin). The attrition rate between the first and last self-rated health measurement wave ranged between $31.2 \%$ to $42.7 \%$ across the four panels.

As discussed above, the health measure was available annually. Other variables were available multiple times a year. We thus first annualized the SIPP data containing these variables for each panel, merged them with the annual health data, and pooled the annual data across four panels to conduct longitudinal analyses. We pooled the four panels of SIPP to obtain a broader understanding of immigrant and native-born health over an extended time span (1996-2013). We also tested for interactions between the health trend and survey panel, which were not significant, suggesting that the health pattern held across the four panels. The sample was restricted to individuals aged 18-56 in the first wave of each panel. We further restricted the sample to respondents with health information for at least two years in each panel. The final sample size is 422,275 person-year observations (149,821 individuals). 


\subsection{Measures}

The dependent variable was self-rated health (SRH). It was the most frequently asked health question in SIPP that captures overall health status. Previous research suggests that SRH is a reasonably good measure of health and is correlated with clinical health assessments and mortality (Chandola and Jenkinson 2000; Idler \& Benyamini, 1997; Franzini \& FernandezEsquer, 2004). The measure was derived from the question: "Would you say your health in general is excellent, very good, good, fair, or poor?". We treated SRH as a linear variable in the analysis, rather than dichotomizing it, to better capture subtle changes across the entire spectrum of SRH categories. This was important because health status was measured up to 4 years and for many people, change over this time in SRH may be modest. We recoded the variable so that higher values indicated better health. We conducted additional analyses including dichotomous dependent variables, with excellent/very good health coded as 1 (and 0 otherwise). The results were largely consistent. It is important to note that different racial/ethnic and national-origin groups of immigrants may vary in their tendencies to endorse certain SRH response categories. For example, Latin American are less likely to state that their health is "excellent" and more likely to rate their health as poor compared to other immigrants and the native population (Lommel and Chen 2016; Shetterly et al. 1996). We partly adjusted for possible cultural differences by controlling for race/ethnicity and distinguishing immigrants from different sending regions. As discussed below, longitudinal fixed-effects models also helped capture some of this tendency.

The key independent variable was immigration status. It was operationalized in three 
ways. We first constructed a dichotomous variable indicating whether the respondent was an immigrant, defined as born outside the U.S. (foreign-born). We further distinguished four year since immigration categories for immigrants (YSI), measured at the first year of survey in each panel. We operationalized two YSI variables. The first followed previous studies to distinguish the following groups: $0-5,6-10,11-20$, and $>20$ years. The second distinguished immigrants with 0-2 years and 3-4 years stay to allow for direct comparison with our longitudinal analysis, which was based on health data for up to 4 years. We also constructed a categorical variable indicating immigrants' region of origin: Mexico, Central America, and Caribbean; South America; Europe; Africa and Middle East; and Asia.

For cohort of arrival, we distinguished immigrant cohorts arriving in 10-year intervals, measured at the baseline of the survey: before 1970,1970s, 1980s, 1990s, and after 2000. We also included a continuous time variable in the longitudinal analysis, which denoted the number of years since the base year of each panel. This variable ranged from 0 to 3 . We included a set of dummy variables indicating the panel of SIPP $(1996,2001,2004,2008)$.

Other control variables included age at the base year (a series of dummy variables 18-20; $21-25 ; 26-30 ; 31-35 ; 36-40 ; 41-45 ; 46-50 ; 51-56$ ), gender, race (non-Hispanic White, nonHispanic Black, Hispanic, Asian, Other), marital status (married vs. not married), and education (less than high school; high school; some college or associate degree; Bachelor's degree or higher). We also controlled for poverty status, defined as annual family income below the $100 \%$ of federal poverty threshold, and health insurance status, defined as whether the individual had any type of public or private health insurance in the previous year. We additionally adjusted for 
geographical variables, including region (Northeast, Midwest, South, and West) and metropolitan status.

The level of missing data was quite low. In the analysis, we drop cases with missing data on any of the variables included, which together accounted for $9.8 \%$ of the person-year observations.

\subsection{Analyses}

We first used SIPP as a stacked sample of repeated cross-sections by including the first observed year of data in each panel. This allowed us to contrast these results with previous studies based on cross-sectional data (using the first set of YSI dummy variables, which distinguished 0-5, 6$10,11-20$, and $>20$ year immigrants), and with our longitudinal estimates (using the second set of YSI dummy variables, which distinguished 0-2 and 3-4 year immigrants). Specifically, we estimated ordinal logistic and OLS regressions to examine how SRH varies with year since immigration, net of cohort of arrival and other covariates.

For longitudinal analysis, we restructured the data as person-year observations and estimated two-level mixed-effects ordinal logistic and linear regressions. These models, based on maximum likelihood estimation, estimated the SRH trajectories while simultaneously accounting for both within-person change over time and between-person variation in individual change over time (Singer \& Willett, 2003). We included random slopes to allow for individuals to vary in their rates of health change. To assess whether the SRH trajectories of immigrants and the native-born population differ, we first included an interaction term between time and the 
dichotomous foreign-born status. In the second model, we replaced the binary foreign-born variable with YSI dummy variables, and included interactions between time and YSI. In the third model, we replaced YSI with immigrants' region of origin and included its interaction with time. For both the cross-sectional models and random-effects models, we excluded one arrival cohort dummy variable (cohort arriving after 2000) in order to identify both the duration effects and the cohort of arrival effects, following earlier research (Antecol \& Bedard 2006).

As a further step, we estimated fixed-effects linear regressions (Gunasekara et al. 2014). The fixed-effects models offer the advantage of controlling for stable individual characteristics (measured and unmeasured) by using within-individual change to estimate the regression coefficients. This approach helps reduce bias from unobserved confounding, such as individual propensities in interpreting and evaluating one's health (e.g., whether a person was more or less likely to report good health, independent of their actual health status) and cultural tendency in endorsing certain SRH response categories. The coefficients of time-invariant variables (immigration status, period of arrival, sex, age in the first wave, race/ethnicity, and survey panel) were absorbed in the fixed effects and not explicitly estimated in these models. An identification strategy is to interact these time-invariant variables with time (Allison 2009), which is what we did. Note that fixed-effects models cannot be estimated with ordinal outcome variables. Thus, we reported mixed-effects linear regressions to permit comparison to the linear fixed-effects models. We derived coefficients and 95\% confidence intervals from all models. We performed all analyses using Stata 15 (StataCorp, 2017). 


\section{Results}

Table 1 displays the descriptive statistics, which is based on the first year of the panel data. Immigrants were slightly younger, more likely to be married, had lower levels of education, more likely to be in poverty, and less likely to have health insurance than the native-born population. They were also more concentrated in metropolitan areas and in the West than the native-born. With respect to sample composition, $49 \%$ of immigrants were from Mexico and Central America, 6\% from South America, 14\% from Europe, 5\% from Africa and Middle East, and $26 \%$ from Asia. On average immigrants and the native-born population reported similar general health status, although the proportion of immigrants reporting excellent or very good health was lower than that of the native-born population (62\% vs. $65 \%)$. The difference should be interpreted with caution because it did not adjust for differences in other characteristics between the two groups.

We further distinguished immigrants by year since immigration. The proportion of female immigrants was higher among those in the country for a relatively shorter duration. Earlier immigrants were more likely to be married than more recent immigrants. There was also evidence that earlier immigrants were more educated, less likely to be in poverty, and more likely to have health insurance. For example, about $54 \%$ of immigrants who arrived more than 20 years ago had at least some college education, which was true for $48 \%$ of immigrants who were in the country for 5 years or less. With respect to self-rated health, the percentage of immigrants who reported excellent or very good health was lower $(58 \%)$ for those in the country for 20 years or longer than for those in the country for 5 years or less $(66 \%)$. These results were 
consistent with earlier studies that point to a health deterioration associated with longer duration of residence.

[Table 1 about here]

Table 2 shows the cross-sectional results based on ordinal logistic regressions (corresponding linear regression models are shown in Appendix A). All YSI groups reported better health than the native-born population. But immigrants' health advantage seemed to deteriorate monotonically with longer duration of stay (Model 1). This was consistent with previous cross-sectional studies that posited a process of unhealthy acculturation. However, after adjusting for cohorts of arrival in Model 2, this monotonic pattern disappeared. Those in the country for 6-10 years appeared to have the best SRH, followed by those with 11-20 years of duration of residence. Immigrants in the country for more than 20 years had the smallest health advantage. This was aligned with previous research suggesting that after accounting for cohort of arrival, the erosion of immigrants' health advantage over longer duration of residence no longer held (Hamilton and Hummer 2011). Model 3 and 4 conducted corresponding analysis measuring change in health in smaller increments of YSI (i.e., 0-2 and 3-4 years). The results pointed to a pattern of unhealthy assimilation, as the magnitude of coefficient decreases over successive YSI groups. The pattern remained even after adjusting for cohort of arrival.

[Table 2 about here] 
As for arrival cohorts, the most recently arrived cohort (after 2000, the reference group) reported better health than all earlier arrival cohorts (Model 2). There was generally a pattern of declining health over successive cohorts, with immigrants who arrived before 1970 reporting the worst health, followed by those arriving in the 1970s, and then those who arrived later. Thus, without adjusting for cohort of arrival, one is likely to conclude with a negative association between YSI and health. But this association is spurious because it reflects the pattern that more recent arrivals were healthier.

Table 3 displays results from longitudinal random-effects ordinal logit regressions. Corresponding mixed-effects linear regressions are displayed in Table 4, which show consistent results. Immigrants reported better health than the native-born population in the base year (Model 1). The coefficient for the year variable indicated the average rate of annual change in SRH for the native born. In other words, over the period of study, SRH declined for the nativeborn population. The interaction between time and foreign-born status was positive and significant. It captured the difference in health trend between immigrants and the native born. It showed that the over-time health change was more positive for immigrants than for natives. The negative main effect of time and positive interaction term between year and foreign-born status together captured the rate of health change for immigrants: they canceled each other out and led to a null relationship between time and health among immigrants. This suggested a stable health trend in SRH for immigrants over the short term. Correspondingly, we could estimate a similar set of models, changing the reference category to foreign-born (Appendix B). Once the reference category was changed, the year coefficient reflected the health trend for immigrants, which, in our case, was insignificant. This pattern was consistent with scenario C in Figure 1. 
[Table 3 and 4 about here]

These results held when we disaggregated immigrants by YSI (Model 2). There was a health decline over time for the native-born population. But the interactions between time and YSI dummy variables were all positive and significant. As such, there was no significant health change for immigrants of different duration of stay. The stable immigrant health, together with a decline health for the native-born, suggested that immigrants' health advantage persisted over the relatively short period under study. Also, the results show that the relationship between YSI and SRH was not linear. Whereas immigrants of all YSI groups reported better health than the native-born at the base year, the health advantage was particularly strong for immigrants in the country for 11-20 years, followed by those in the country for over 20 years, with 6-10 YSI immigrants having the least health advantage. These patterns were summarized in Figure 2. It showed an initial health advantage and a generally stable health trend for four YSI groups of immigrants and a decline for the native born.

[Figure 2 about here]

Model 3 showed interesting variations by region of origin. As in the previous models, a health decline for the native-born was observed. The interactions between time and region dummy variables were positive for Mexican, Central American and South American immigrants, and for Asian immigrants. These immigrant groups did not experience a decline in SRH as the native-born population did. For European and African immigrants, the interaction terms were 
non-significant. Hence, these immigrants experienced a health deterioration at a similar level to the native born. At the base year, there were some differences by immigrants' region of origin. Immigrants from Latin America and Europe reported better health than the native born. The opposite was true for Asian immigrants. For Asian immigrants, this pattern resulted from their high education. The opposite pattern (health advantage) was obtained without adjusting for education. These results suggested that the initial level and trend in SRH was not uniform across immigrants from different regions, as displayed in Figure 3. Four origin groups (except for Asian immigrants) showed a baseline health advantage relative to the native born. Over time, various origin groups of immigrants showed more or less a stable health trend (similar to scenario $\mathrm{C}$ in Figure 1): Latin American immigrants and Asian immigrants seemed to experience, respectively, a slight increase and a slight decline, but these trends were not statistically significant. The exception was European immigrants, who experienced the same rate of health decline as the native-born population. But even for this group, their initial health advantage over the native born continued (scenario E in Figure 1).

[Figure 3 about here]

Results from fixed-effects models were presented in Table 5. These models further adjusted for time-invariant unobserved confounding factors. Note that coefficients of stable variables, such as gender, immigration status (by YSI and region), race, and cohort of arrival were not reported but effectively adjusted for. In general, the substantive results were similar to those reported in the mixed-effects regressions: while for the native born SRH declined over time, this was not the case for immigrants. Immigrants experienced a stable trend in SRH and the 
immigrant-native difference was statistically significant (positive interaction terms). This pattern held true for immigrants with different durations of residence, and for those originally from Mexico, Central and South America, and Asia.

[Table 5 about here]

We conducted a series of sensitivity analyses to evaluate the robustness of our results to different model specifications and sample attrition. First, we carried out an additional analysis using non-Hispanic White native-born as the reference group (Appendix C). In another analysis (Appendix D), we included logged total family income (adjusted for inflation) as a measure of socioeconomic position to replace poverty status. The results in both analyses were very similar to the main analysis. Moreover, we conducted sensitivity analysis that restricted the analytic sample to respondents with annual health information throughout each panel (Appendix E). The results were largely consistent, suggesting that sample attrition did not change our main findings.

\section{Conclusion}

We investigated whether immigrants experience unhealthy assimilation using longitudinal data, by comparing the health trajectories of immigrants and the native-born population. Results suggest that during 1996-2013, immigrants maintained their health advantage over the nativeborn over the 2-4 years of study. This was manifested by a decline in SRH for the native-born population, but a stable trend for immigrants during the same period. The difference between the immigrant and native-born rate of health change was statistically significant. These results held when we disaggregated immigrants by duration of residence. In other words, immigrants across 
various durations of residence exhibited more favorable health trajectories than their native-born counterparts. Moreover, the trend in SRH varied by region of origin. Latin American and Asian immigrants were particularly likely to sustain their health advantage over the native-born population. Immigrants from other regions experienced a health decline over time at a similar rate as the native born. Even so, their health advantage over the native born still persisted.

Our study sheds light on the importance of using longitudinal data to directly compare health trajectories of immigrants and the native-born population. Only by using longitudinal data can we explicitly model the key process of interest - how immigrants' health change over time relative to the change of the native-born population? When such a strategy was adopted, we found no evidence, as postulated by the unhealthy assimilation hypothesis and by our crosssectional analysis, that immigrants' health downwardly converged to that of their native-born counterparts. Rather, there was a steeper deterioration among the native-born than immigrants even over the relatively short period under study. Many immigrants reported a stable SRH status, pointing to their consistent and possibly even widening health advantage. For European immigrants and, to a lesser extent, African immigrants, their SRH seemed to deteriorate over time but at the same rate as the native population, thus also providing evidence against a pattern of health convergence. It is worth noting that while the difference between immigrants and native-born in health was statistically significant, the size of the difference was relatively small. A comparison of the mixed-effects and fixed-effects models, as well as results from a series of sensitivity analyses, suggested that our results were conservative and largely robust to unobserved heterogeneity, model specifications, and sample attrition. 
One plausible explanation that our longitudinal findings differ from cross-sectional results is that the health of immigrants entering the country improved with successive arrival cohorts. This could be a result of a general improvement in population health in sending countries, or an increased degree of immigrant selectivity in areas that are positively associated with health, as a result of the tightening climate for recent immigrants to the United States (Massey and Sanchez 2010). Therefore, immigrants who arrived at a more recent period tend to exhibit better health than immigrants who arrived at an earlier period (supported by our results; see Table 2). Earlier cohorts of arrival also correlate with a longer duration of stay. Thus, the observed negative relationship between health and duration of stay in cross-sectional data could be largely confounded by cohort of arrival effects.

Findings from this study suggest that immigrants' health change over time is a more complex process than previously perceived. At the same time unhealthy acculturation unfolds, immigrants also experience other social and economic changes (economic assimilation) that may ultimately have positive health implications. For example, over the course of integration into the host society, immigrants often improve their economic condition and access to health care, both facilitating good health (Marmot and Bell 2012; Wong et al. 2007). Even for the group of immigrants who enter the country with low incomes and limited health access, many of them subsequently close gaps with the native-born over the course of their residence (Antecol, Kuhn, and Trejo 2006). Also, a notable proportion of immigrants come from less developed sending countries. Upon arriving in the U.S., they tend to enjoy more favorable economic conditions than back in their home country. These processes, namely improvement (comparing to the origin country) and assimilation (over the course of their stay in the destination), both predict a 
potential boost to health status. Therefore, whereas the health decline for the native-born largely reflects an aging effect--that is, health deteriorates as people age--immigrants are exposed to a countervailing process of positive economic assimilation, which positive implications for health. This process serves as a protective factor and offsets the negative aging effects. The finding that European immigrants, many of whom are from high income nations with well-developed public health systems, experienced the least favorable health trend than other immigrant groups may be instructive. This difference may be partially attributed to their limited changes in socioeconomic conditions between origin and destination, as many European sending countries are more developed than sending countries from Africa, Asia, and Latin America. Overall, the adoption of unhealthy practices and improvement in economic conditions and health care access are likely to offset the effect of each other. In combination, they lead to stable health trajectories of immigrants, as we observed in this study.

A few limitations need to be noted. First, we were limited to studying the short-term health trajectories because SIPP panels are relatively short. Acculturation and socioeconomic mobility may unfold over a longer period of time, not in the years observed in this study. A longer longitudinal survey would be needed to determine whether the longer-term health trajectories of immigrants continue or change course. Second, our analysis relied on perceived health given data availability. It remains a question whether other health measures exhibit similar or different over-time patterns. The patterns may unfold differently for other, more objective health measures, such as BMI, which are particularly sensitive to the process of unhealthy acculturation. A recent longitudinal study points to a positive relationship between BMI and longer duration of residence for certain subgroups of Hispanic immigrants (Albrecht et al. 2013). 
Also, despite being a reasonably good predictor of morbidity and mortality, SRH can be subject to differences in reporting and in perceptions of health. We attempted to account for some of these differences through the use of longitudinal fixed-effects regressions and controlling for race/ethnicity. These strategies, while may not completely account for the cultural differences in interpreting and responding to the SRH question, help to adjust for some of the differences for us to reach a more meaningful conclusion. Given that some immigrant groups (e.g., Latin American) are less likely to report their health as excellent, our findings of a persistent health advantage would be on the conservative side. Still, one may expect that immigrants tend to change their reference point to which they compare themselves (e.g., longer-stay immigrants change their reference group from people in their country of origin to those in the country of destination). It may be difficult to disentangle real health change from change in perceptions (DuBard and Massing 2007). Unfortunately, the data do not provide information on the group of comparison when evaluating health. But the health trajectories we identified held for all YSI groups, including immigrants with a long duration of stay, which were unlikely to change their reference point during the study period. This suggests that possible change in reference point did not account for all the results.

Our study demonstrated the importance of using longitudinal data to study immigrant health in order to obtain a more accurate understanding of the health assimilation process. Given the paucity of national-level longitudinal data with health indicators and a sufficient sample size of immigrants, the advantages of SIPP outweighed its limitations. It is a fruitful direction for future studies to incorporate longitudinal physical health measures and contrast longer-term health trajectories between immigrants and the native-born population to reveal complex patterns 
in immigrants' health. Conceptually, our findings underscored the complexity of immigrants' health change by focusing not only on the implications of unhealthy acculturation process, but also on potential protective factors that could offset the negative impact of migration (e.g., socioeconomic conditions). While we acknowledge the adverse acculturation process that expose immigrants to health challenges, we believe that attention should also be paid to potential protective factors that serve to counteract these challenges and sustain immigrants' health advantage. Identifying these pathways deserves future study and has important implications for improving services aiming to facilitate immigrants' integration. 


\section{References}

Abraído-Lanza, A. F., Echeverría, S. E., \& Flórez, K. R. (2016). Latino Immigrants, Acculturation, and Health: Promising New Directions in Research. Annual Review of Public Health, 37(1), 219-236.

Acevedo-Garcia, D., Bates, L. M., Osypuk, T. L., \& McArdle, N. (2010). The effect of immigrant generation and duration on self-rated health among US adults 2003-2007. Social Science \& Medicine, 71(6), 1161-1172.

Akresh, I. R. (2007). Dietary assimilation and health among Hispanic immigrants to the United States. Journal of Health and Social Behavior, 48(4), 404-417.

Albrecht, S. S., Roux, A. V. D., Kandula, N. R., Osypuk, T. L., Ni, H. and Shrager, S. (2013). Immigrant assimilation and BMI and waist size: A longitudinal examination among Hispanic and Chinese participants in the multi-ethnic study of atherosclerosis. Obesity, $21,1695-1703$.

Allison, P. D. (2009). Fixed effects regression models (Vol. 160). SAGE publications.

Antecol, H., \& Bedard, K. (2006). Unhealthy assimilation: Why do immigrants converge to American health status levels? Demography, 43(2), 337-360.

Antecol, H., Kuhn, P., \& Trejo, S. J. (2006). Assimilation via prices or quantities? Sources of immigrant earnings growth in Australia, Canada, and the United States. Journal of Human Resources, 41(4), 821-840.

Biddle, N., Kennedy, S., \& McDonald, J. T. (2007). Health assimilation patterns amongst Australian immigrants. Economic Record, 83(260), 16-30.

Borjas, G. J. (1985). Assimilation, changes in cohort quality, and the earnings of immigrants. Journal of Labor Economics, 3(4), 463-489.

Chandola, T., \& Jenkinson, C. (2000). Validating self-rated health in different ethnic groups. Ethnicity and Health, 5(2), 151-159.

Chiswick, B. R., Lee, Y. L., \& Miller, P. W. (2008). Immigrant selection systems and immigrant health. Contemporary Economic Policy, 26(4), 555-578.

Cho, Y., Frisbie, W. P., Hummer, R. A., \& Rogers, R. G. (2004). Nativity, duration of residence, and the health of Hispanic adults in the United States. International Migration Review, 38(1), 184-211.

DuBard, C. A., \& Massing, M. W. (2007). Trends in emergency Medicaid expenditures for recent and undocumented immigrants. JAMA, 297(10), 1085-1092.

Escobar, J. I., Nervi, C. H., \& Gara, M. A. (2000). Immigration and mental health: Mexican Americans in the United States. Harvard review of psychiatry, 8(2), 64-72.

Finch, B. K., \& Vega, W. A. (2003). Acculturation stress, social support, and self-rated health among Latinos in California. Journal of Immigrant Health, 5(3), 109-117.

Franzini, L., \& Fernandez-Esquer, M. E. (2004). Socioeconomic, cultural, and personal influences on health outcomes in low income Mexican-origin individuals in Texas. Social Science \& Medicine, 59(8), 1629-1646.

Gubernskaya, Z. (2015). Age at Migration and Self-Rated Health Trajectories After Age 50: Understanding the Older Immigrant Health Paradox. The Journals of Gerontology Series B: Psychological Sciences and Social Sciences, 70(2), 279-290.

Gunasekara, F. I., Richardson, K., Carter, K., \& Blakely, T. (2014). Fixed effects analysis of repeated measures data. International Journal of Epidemiology, 43(1), 264-269. 
Hamilton, T. G., \& Hummer, R. A. (2011). Immigration and the health of US black adults: does country of origin matter? Social Science \& Medicine, 73(10), 1551-1560.

Hummer, R. A. (1996). Black-white differences in health and mortality: A review and conceptual model. The Sociological Quarterly, 37(1), 105-125.

Hummer, R. A., Powers, D. A., Pullum, S. G., Gossman, G. L., \& Frisbie, W. P. (2007). Paradox found (again): infant mortality among the Mexican-origin population in the United States. Demography, 44(3), 441-457.

Idler, E. L., \& Benyamini, Y. (1997). Self-rated health and mortality: a review of twenty-seven community studies. Journal of Health and Social Behavior, 39(1), 21-37.

Kaestner, R., Pearson, J. A., Keene, D., \& Geronimus, A. T. (2009). Stress, Allostatic Load, and Health of Mexican Immigrants. Social Science Quarterly, 90(5), 1089-1111.

Kim, I.-H., Carrasco, C., Muntaner, C., McKenzie, K., \& Noh, S. (2013). Ethnicity and postmigration health trajectory in new immigrants to Canada. American Journal of Public Health, 103(4), e96-e104.

Lara, M., Gamboa, C., Kahramanian, M. I., Morales, L. S., \& Hayes Bautista, D. E. (2005). Acculturation and Latino health in the United States: a review of the literature and its sociopolitical context. Annu. Rev. Public Health, 26, 367-397.

Lee, S., O’Neill, A., Park, J., Scully, L., \& Shenassa, E. (2012). Health insurance moderates the association between immigrant length of stay and health status. Journal of Immigrant and Minority Health, 14(2), 345-349.

Lommel, L. L., \& Chen, J.-L. (2016). The Relationship Between Self-Rated Health and Acculturation in Hispanic and Asian Adult Immigrants: A Systematic Review. Journal of Immigrant and Minority Health, 18(2), 468-478.

Marmot, M., \& Bell, R. (2012). Fair society, healthy lives. Public health, 126, S4-S10.

Massey, D. S., \& Sánchez, M. (2010). Brokered boundaries: Immigrant identity in antiimmigrant times. Russell Sage Foundation.

Newbold, B. (2005). Health status and health care of immigrants in Canada: a longitudinal analysis. Journal of Health Services Research \& Policy, 10(2), 77-83A.

Ng, E., Wilkins, R., Gendron, F., \& Berthelot, J. M. (2013). Dynamics of immigrants' health in Canada: evidence from the National Population Health Survey. Ottawa, ON: Statistics Canada; 2005.

Rubalcava, L. N., Teruel, G. M., Thomas, D., \& Goldman, N. (2008). The healthy migrant effect: new findings from the Mexican Family Life Survey. Journal Information, 98(1).

Shetterly, S. M., Baxter, J., Mason, L. D., \& Hamman, R. F. (1996). Self-rated health among Hispanic vs non-Hispanic white adults: the San Luis Valley Health and Aging Study. American Journal of Public Health, 86(12), 1798-1801.

Setia, M. S., Quesnel-Vallee, A., Abrahamowicz, M., Tousignant, P., \& Lynch, J. (2012). Different outcomes for different health measures in immigrants: Evidence from a longitudinal analysis of the national population health survey (1994-2006). Journal of Immigrant and Minority Health, 14(1), 156-165.

Singer, J. D., \& Willett, J. B. (2003). Applied longitudinal data analysis: Modeling change and event occurrence. Oxford university press.

Singh, G. K., \& Miller, B. A. (2004). Health, life expectancy, and mortality patterns among immigrant populations in the United States. Can J Public Health, 95(3), 14-21.

StataCorp. (2017). Stata Statistical Software: Release 15. College Station, TX: StataCorp LP. 
Teitler, J., Martinson, M., \& Reichman, N. E. (2015). Does Life in the United States Take a Toll on Health? Duration of Residence and Birthweight among Six Decades of Immigrants. International Migration Review, 51(1), 37-66.

Wong, S. T., Yoo, G. J., \& Stewart, A. L. (2007). An empirical evaluation of social support and psychological well-being in older Chinese and Korean immigrants. Ethnicity and Health, $12(1), 43-67$. 
Figure 1. Illustration of health trajectories of immigrants and native-born population (five scenarios)

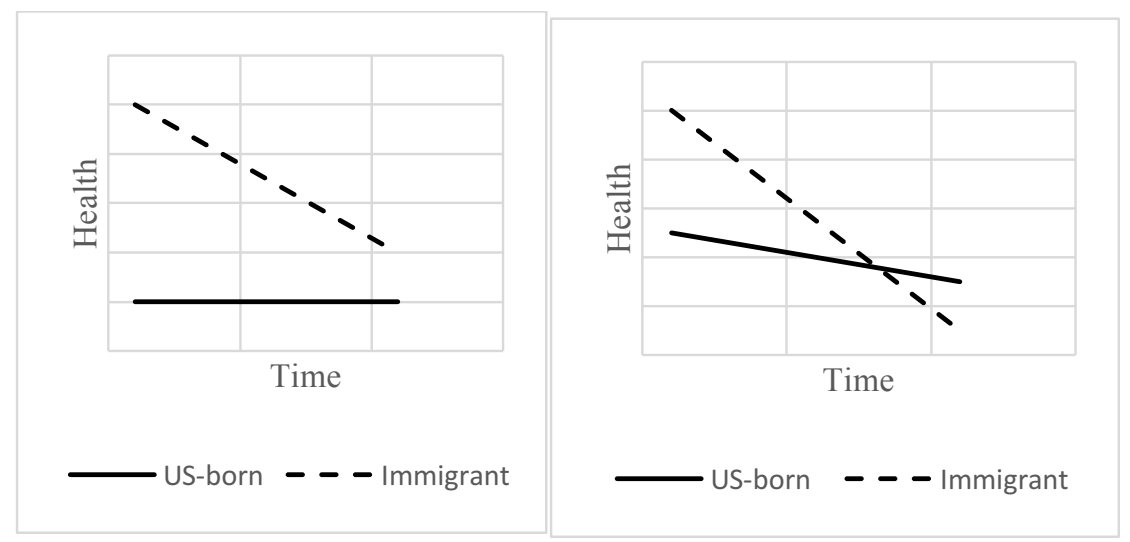

A. Unhealthy assimilation

B. Unhealthy assimilation

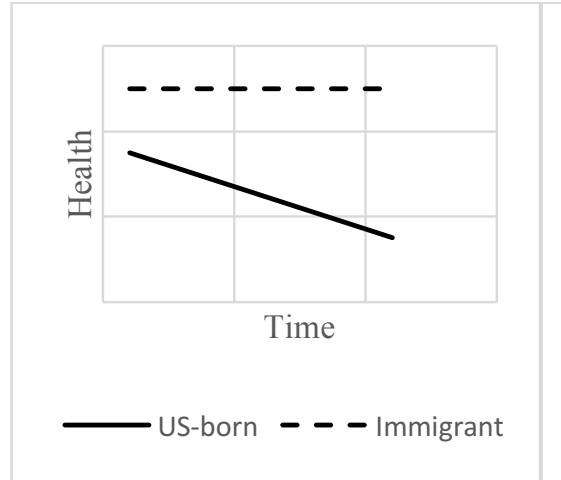

C. Persistent (widening) advantage

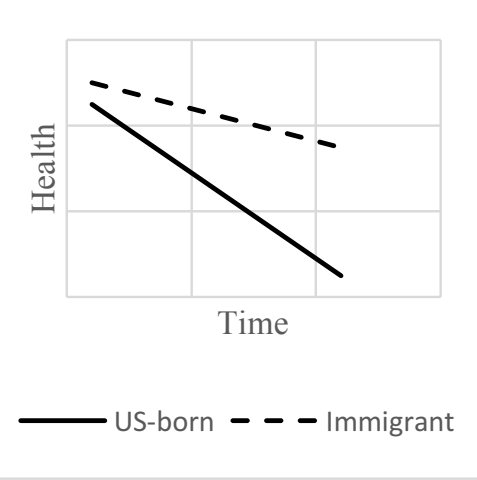

D. Persistent (widening) advantage

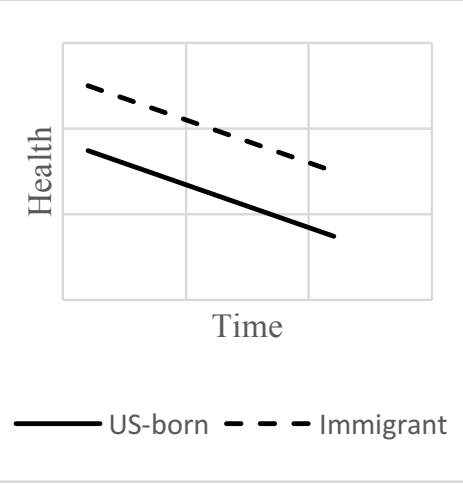

E. Persistent health advantage 
Figure 2. Estimated health trajectories of various immigrant duration groups and the native-born population (based on mixed-effects regressions in Table 3)

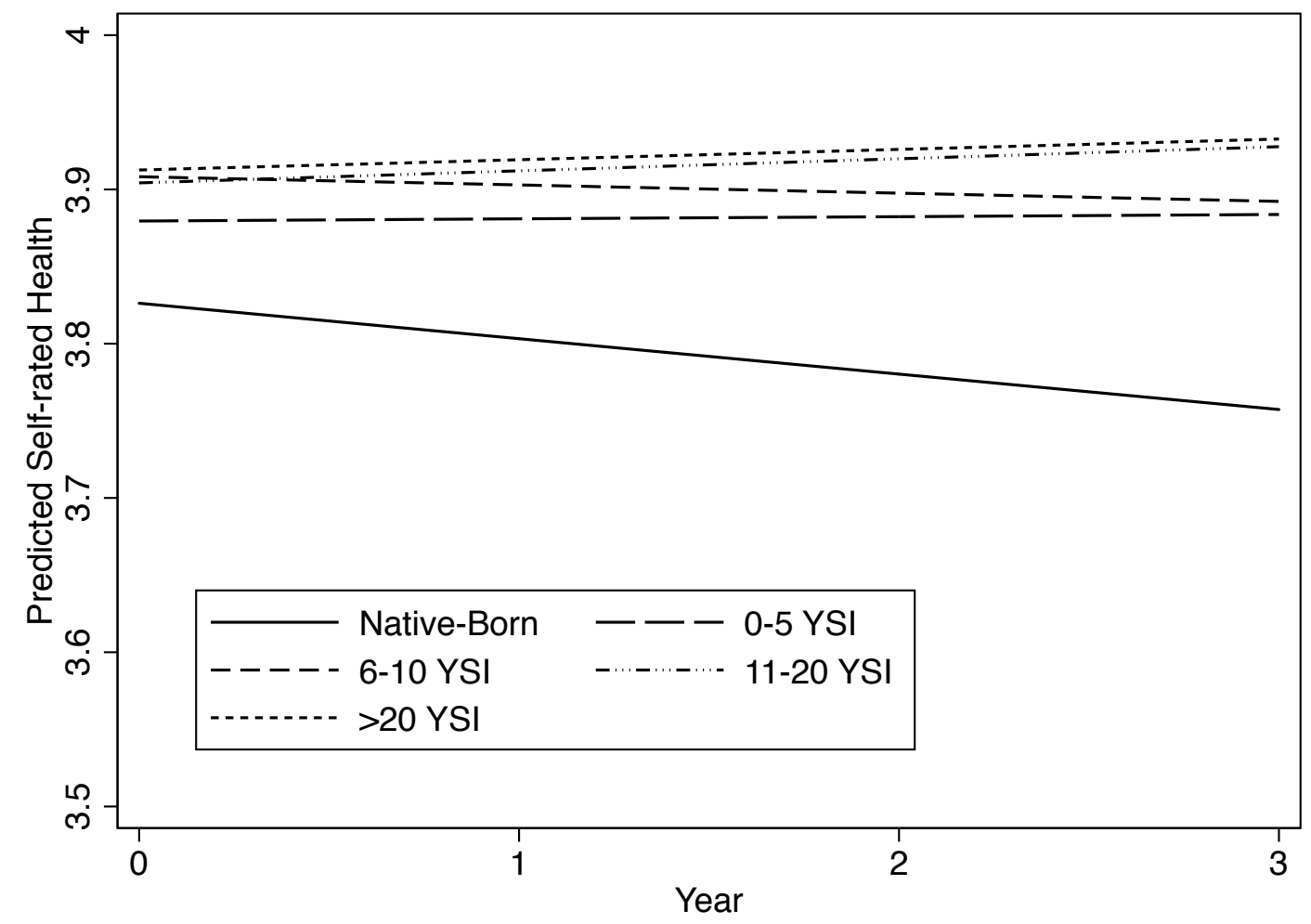


Figure 3. Estimated health trajectories of various immigrant origin groups and the native-born population (based on mixed-effects regressions in Table 3)

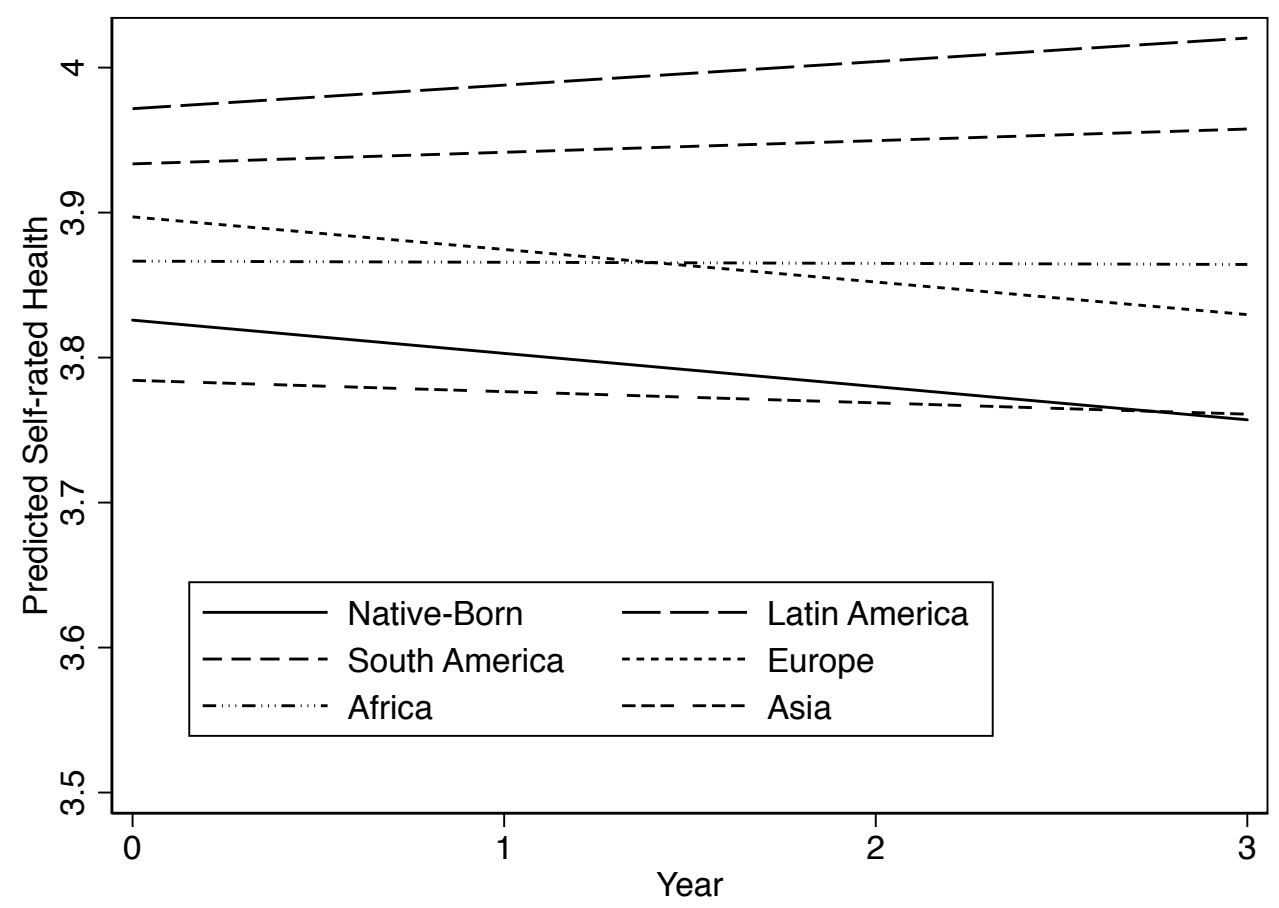




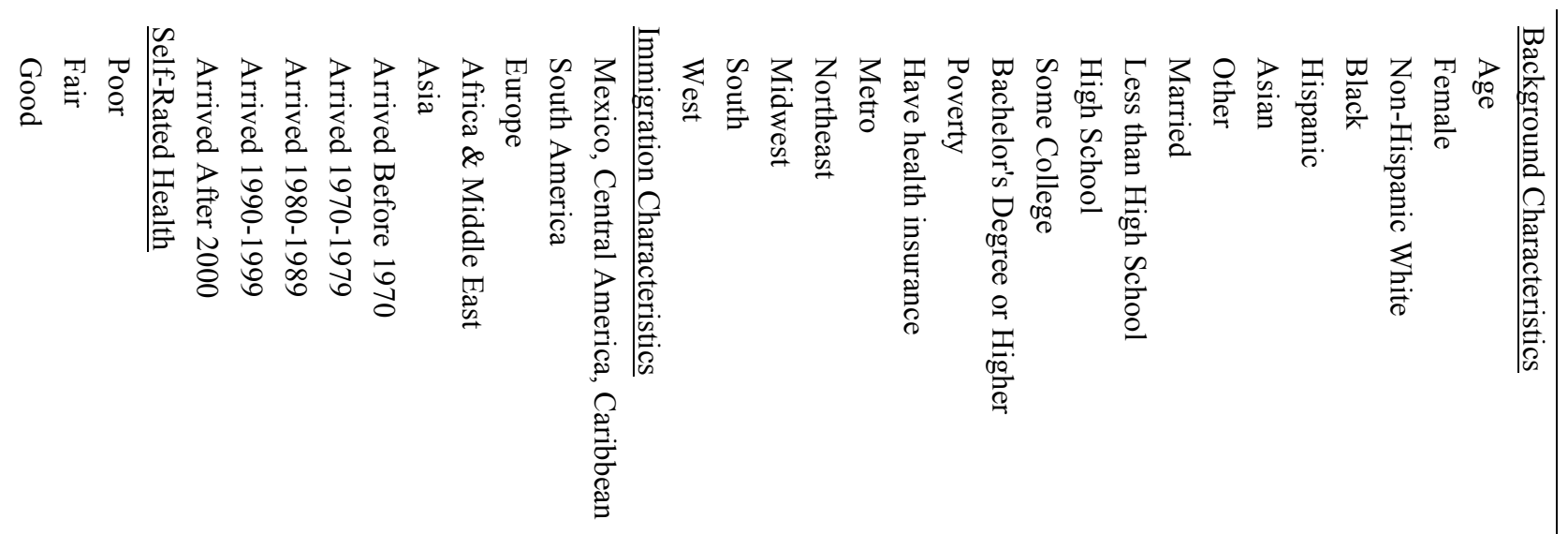

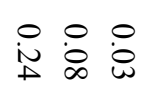

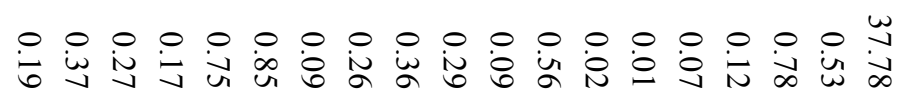

i

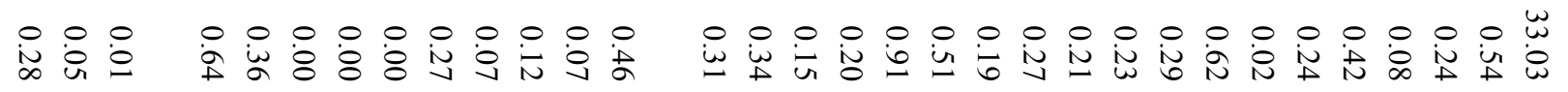

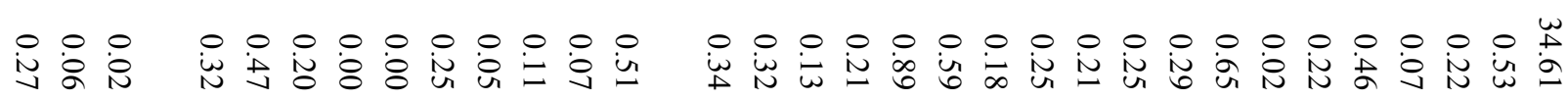

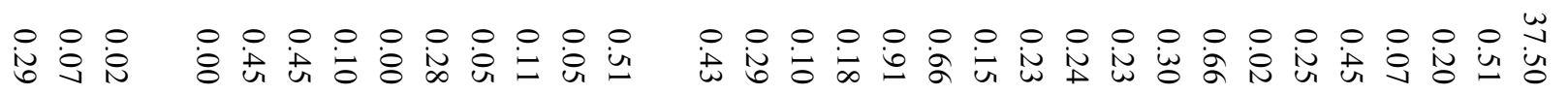

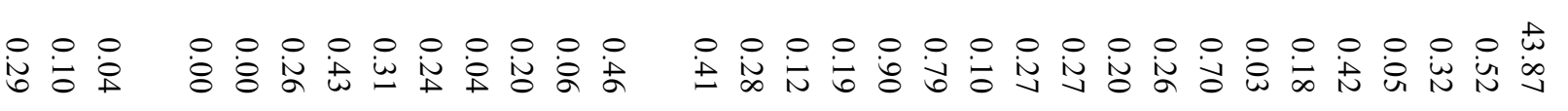




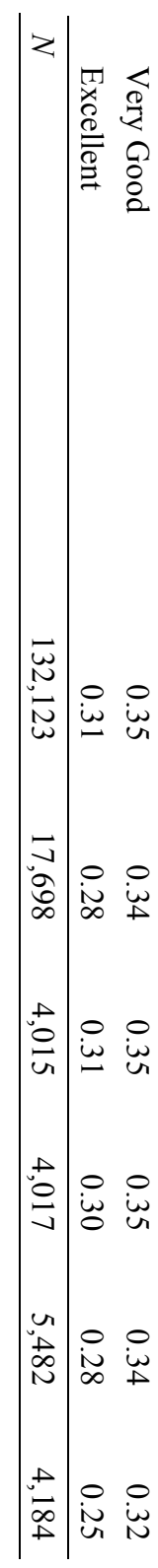




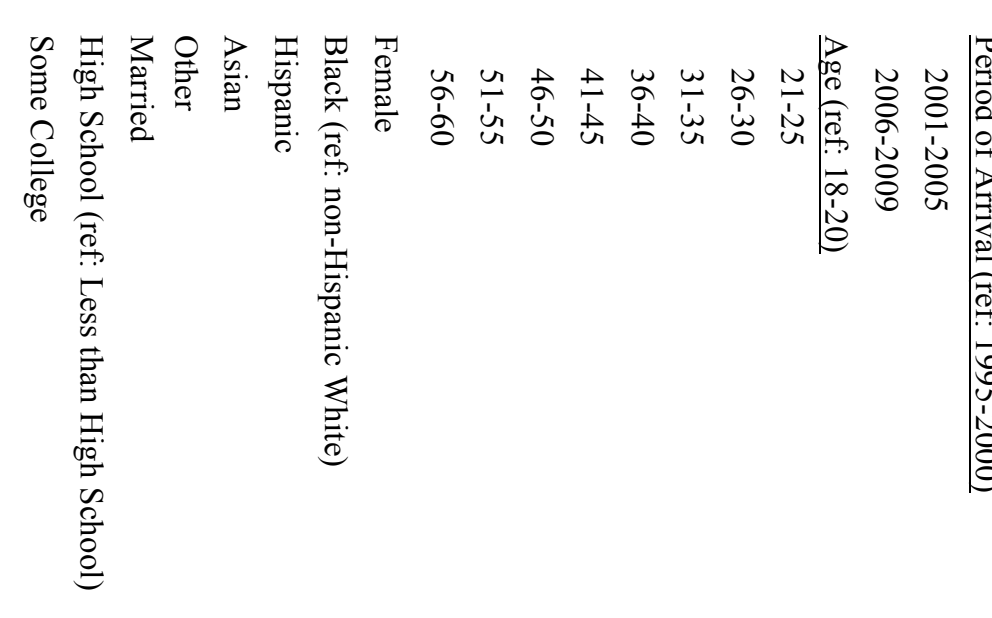

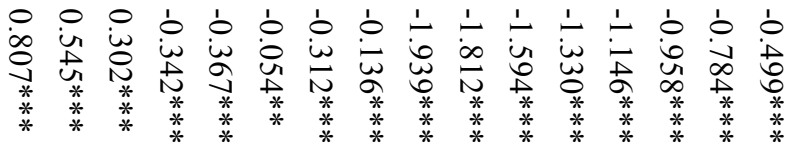

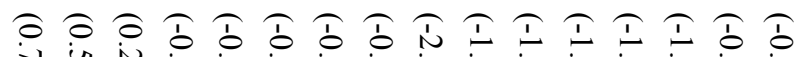
ù

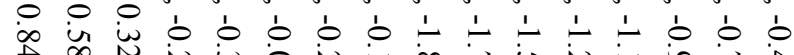

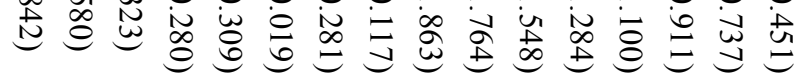

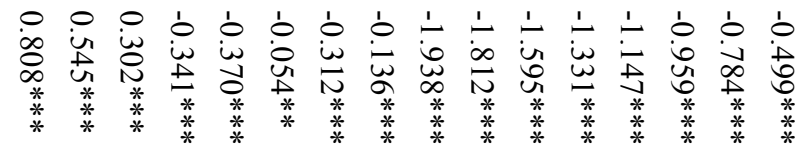

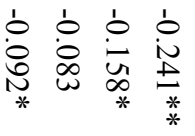

oิ

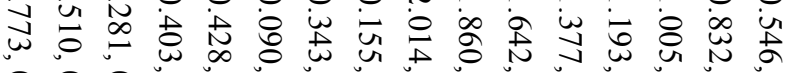
$\circ$ i

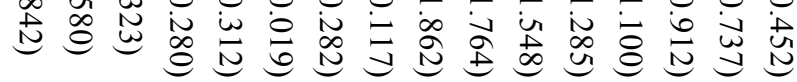

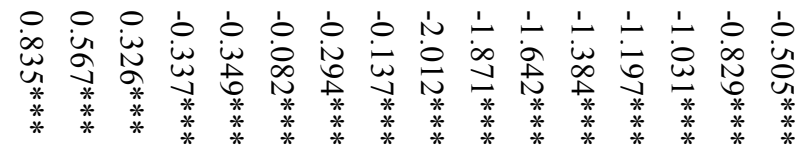

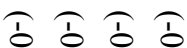

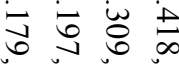

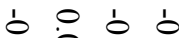

ஓे
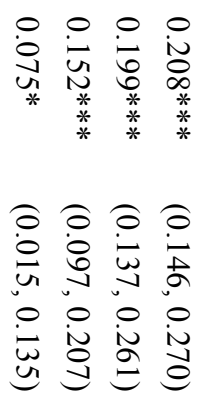

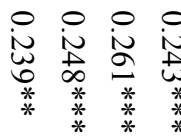
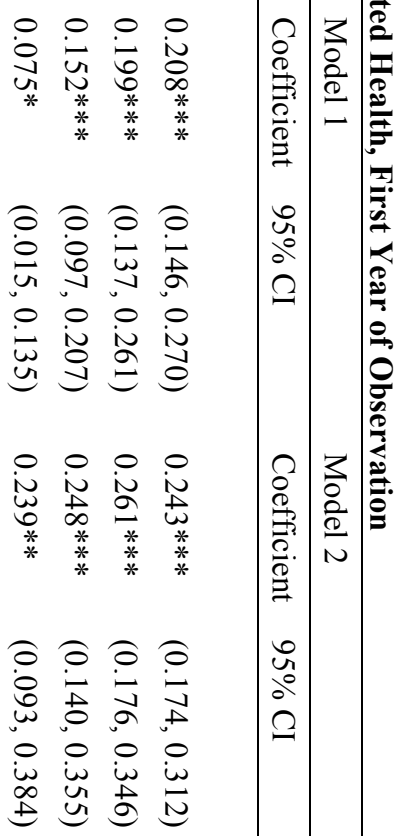

วิ)

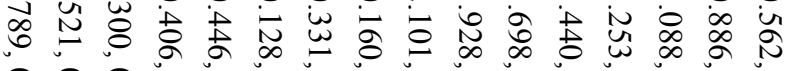

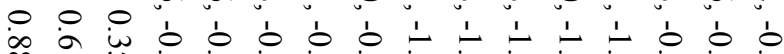

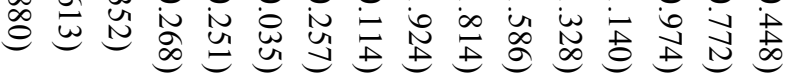

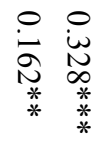

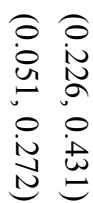

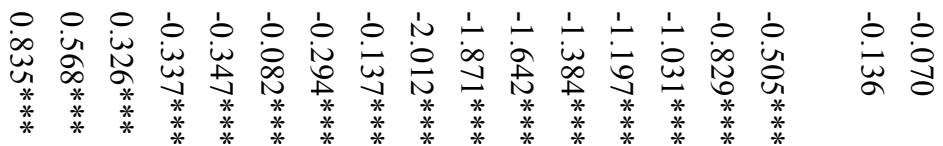

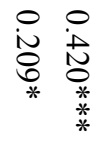

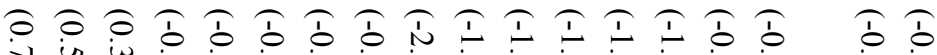

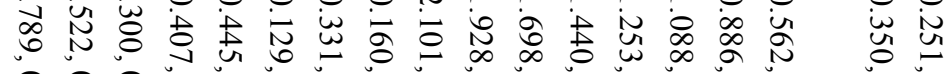

วิ)

美章

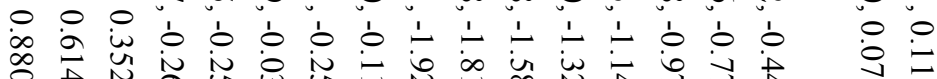

is $i_{i}$ 


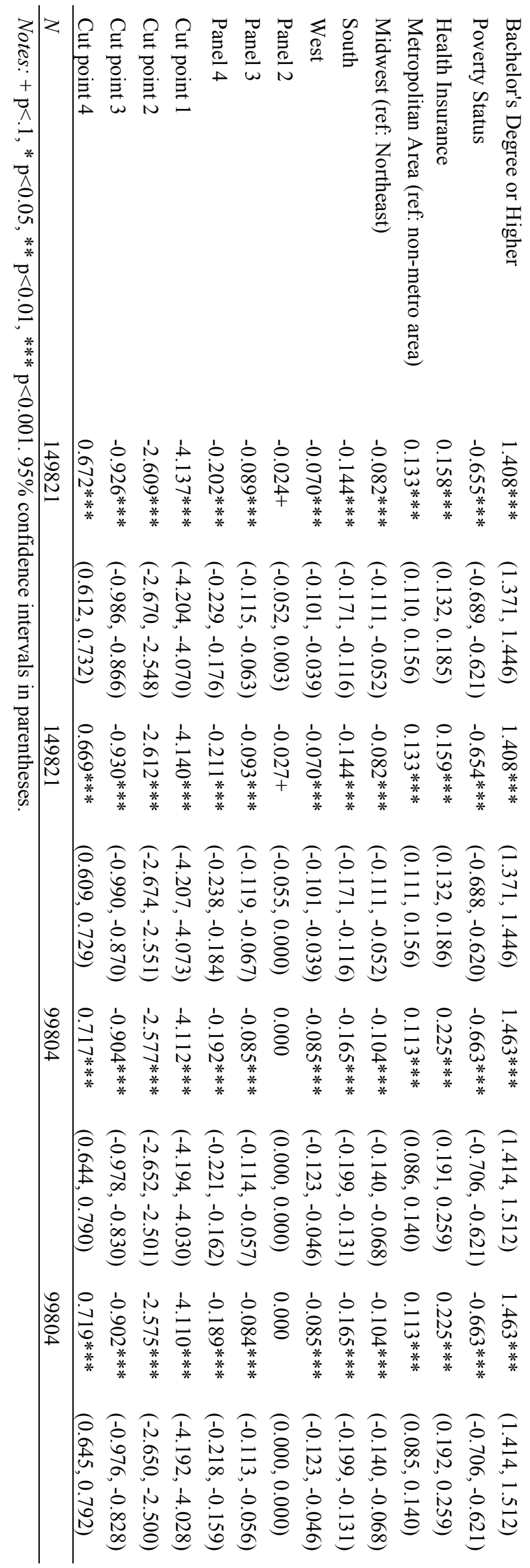




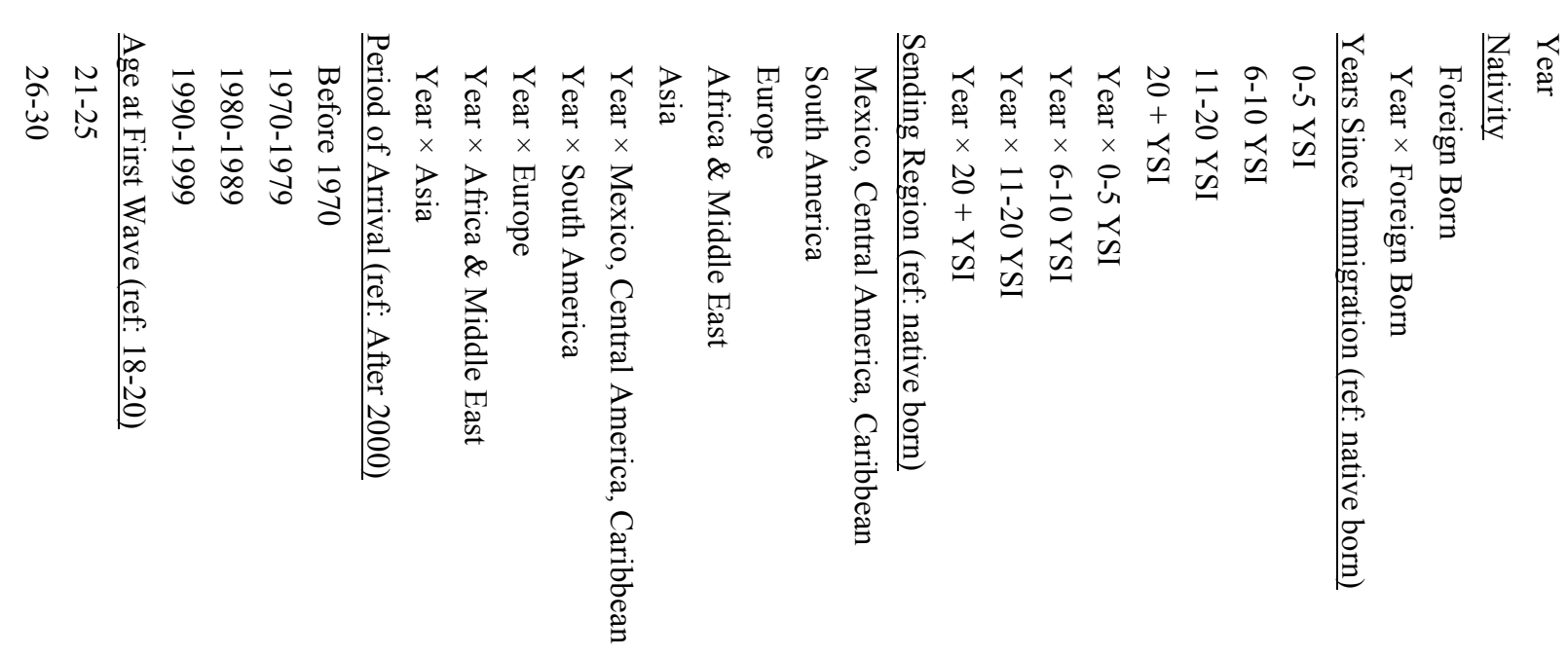

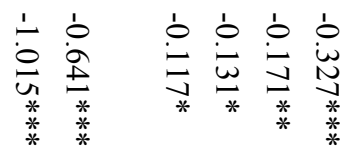

ริ

政

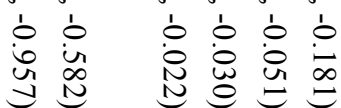

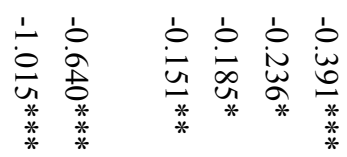

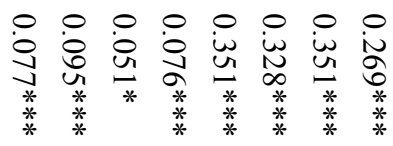

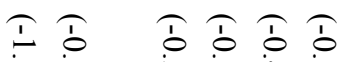

용

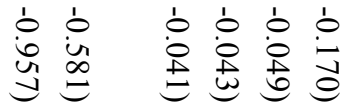

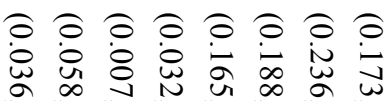

. 0.0 .

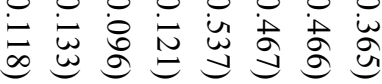

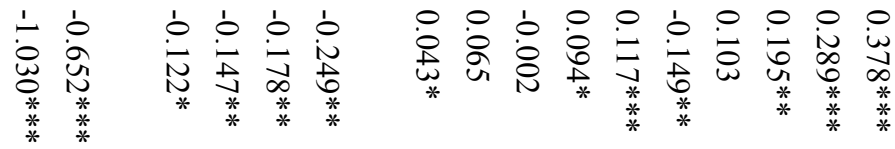

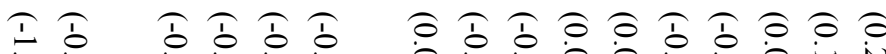

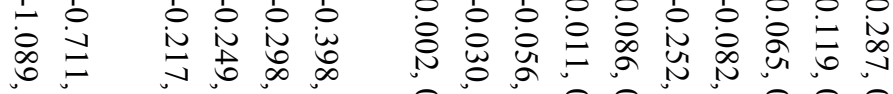

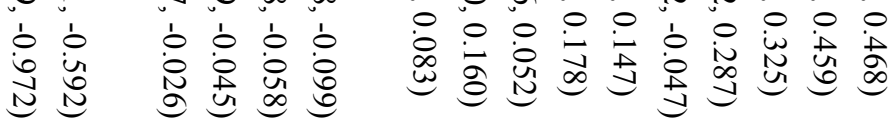




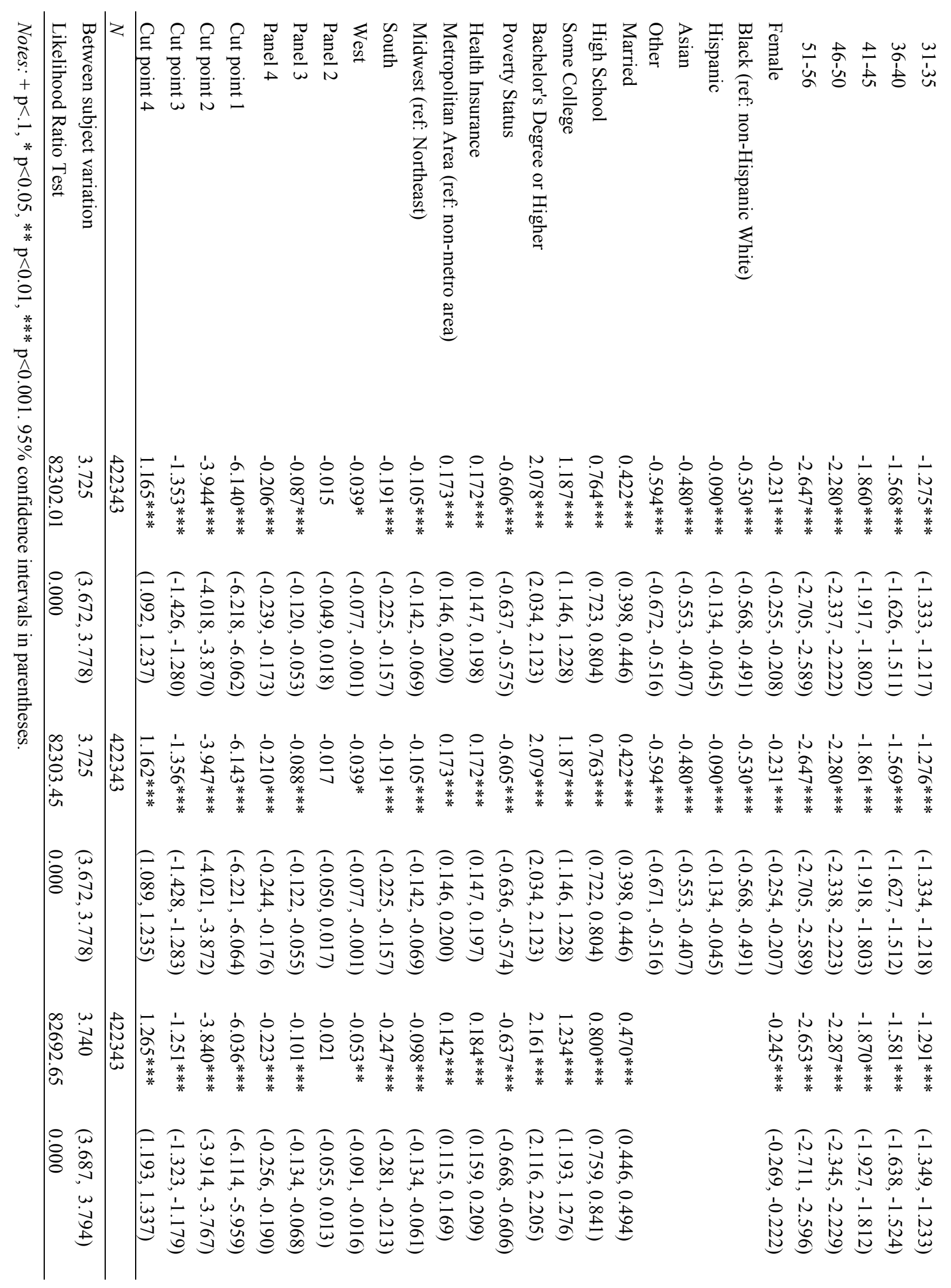




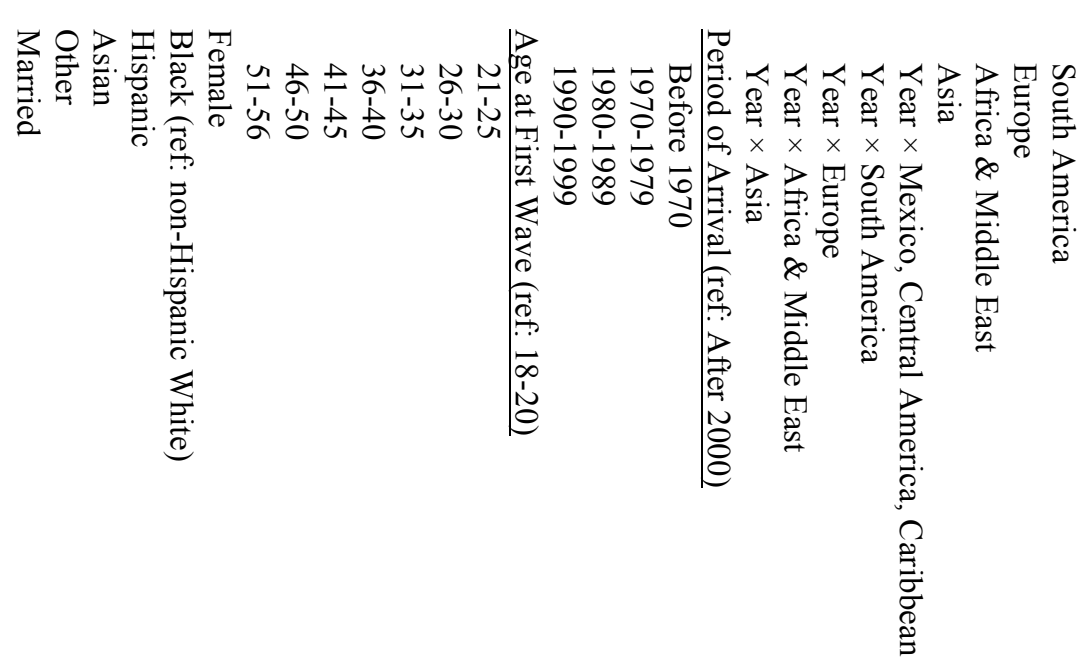

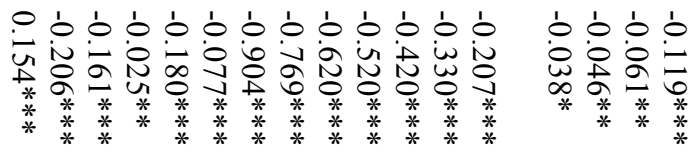

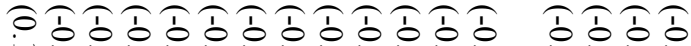

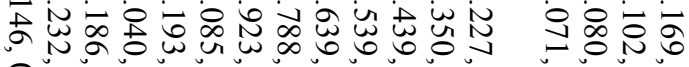

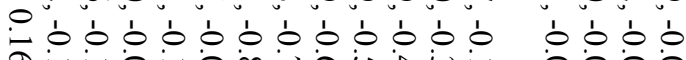

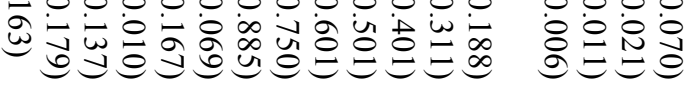

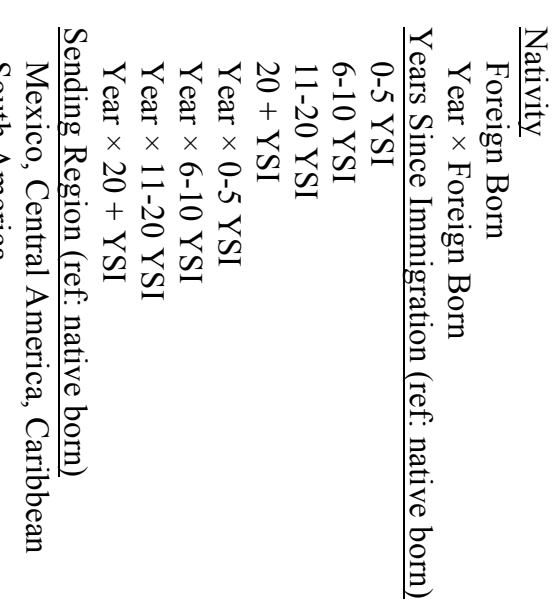

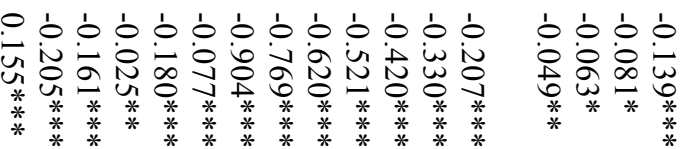

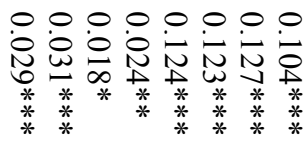

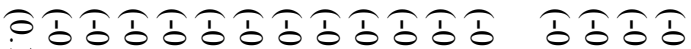

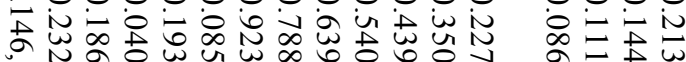

อ.อ.อ.อ.ดองอ

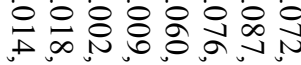

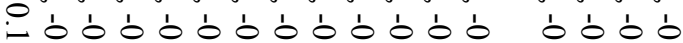

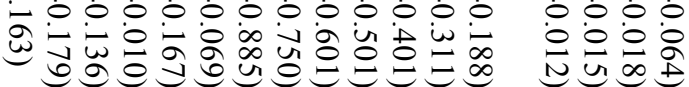

000000000

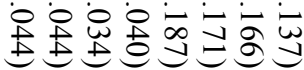

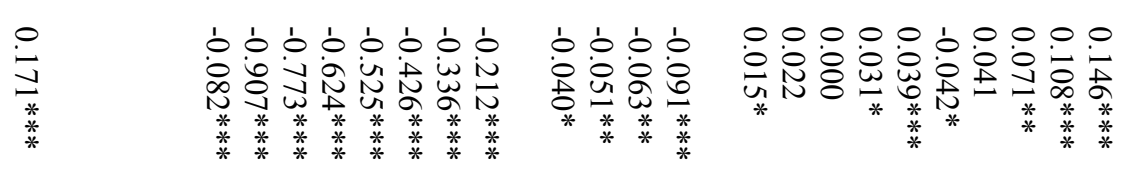

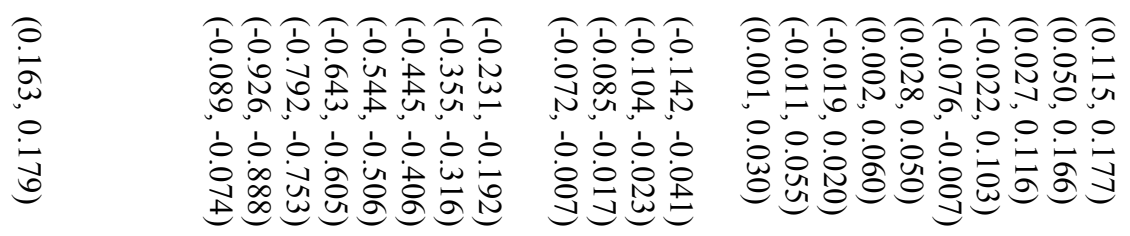

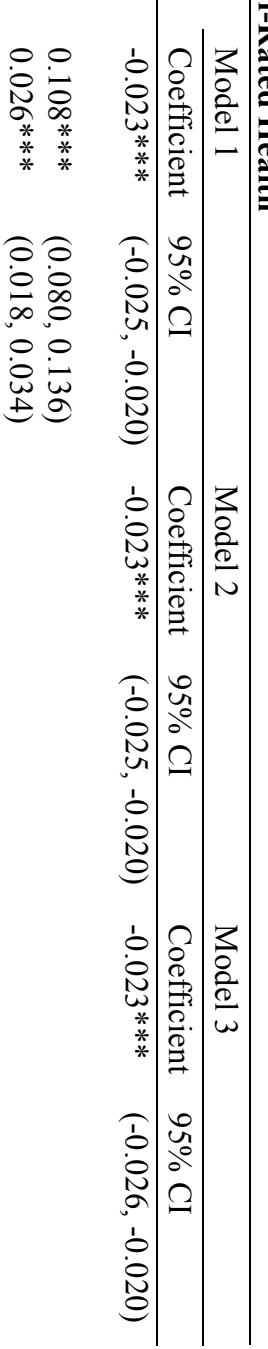




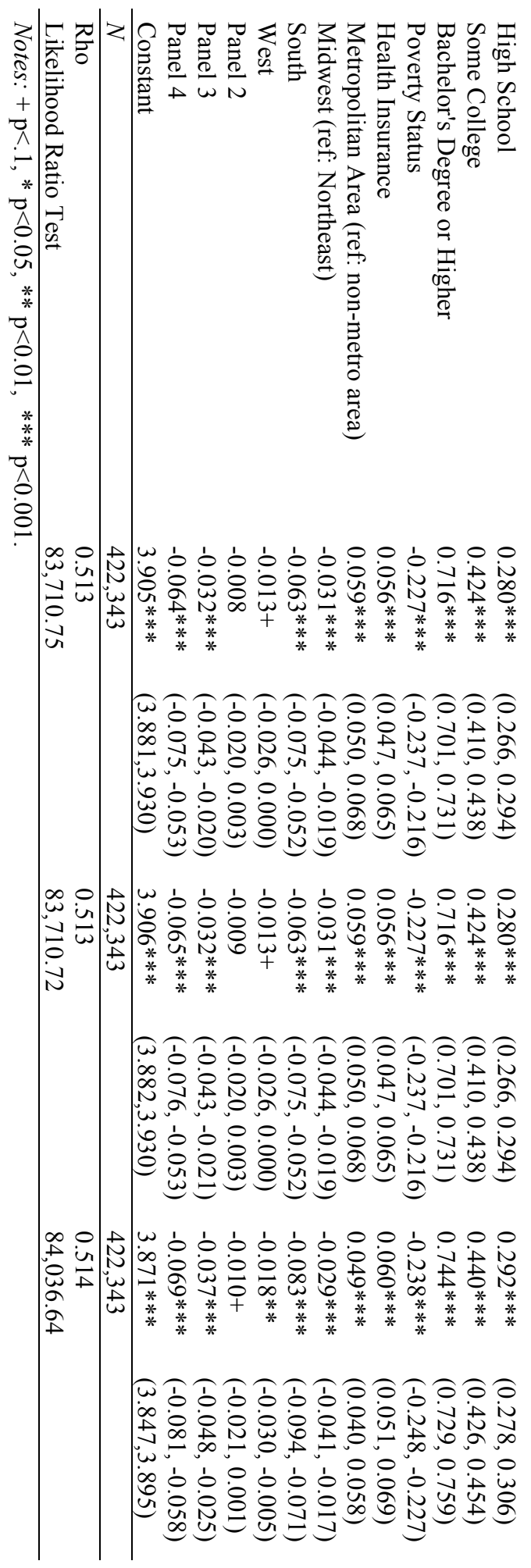




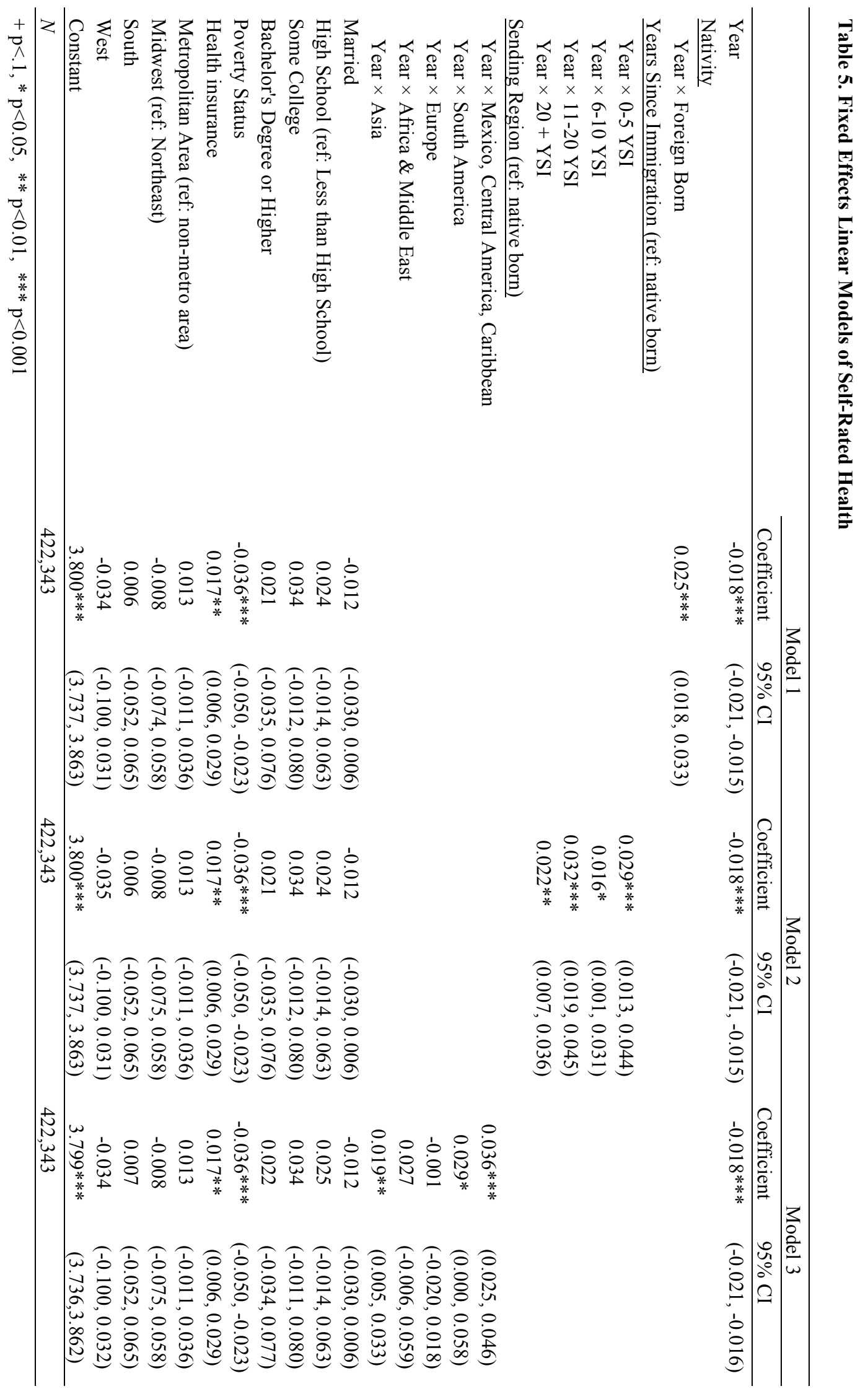




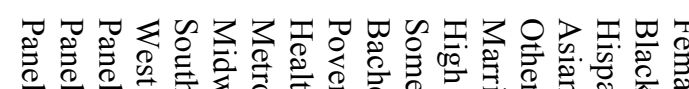

A

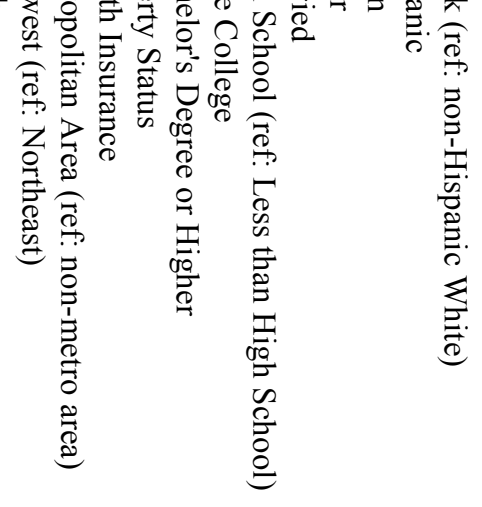

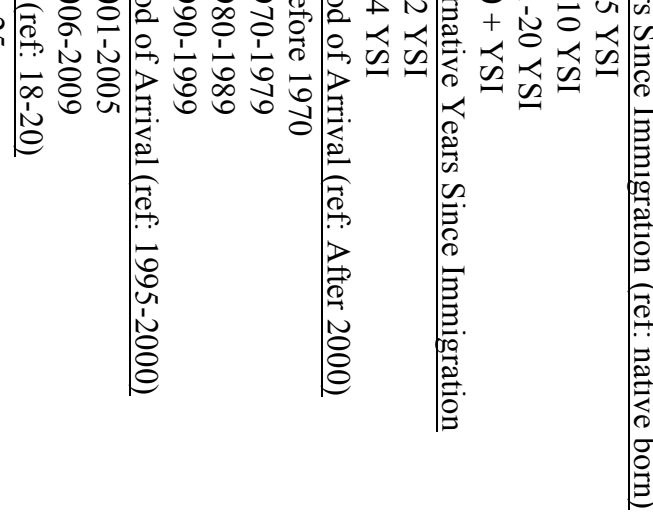

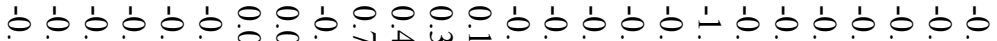

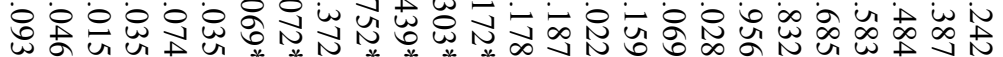

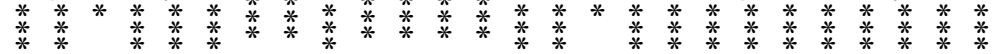

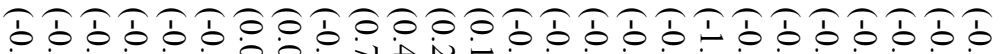

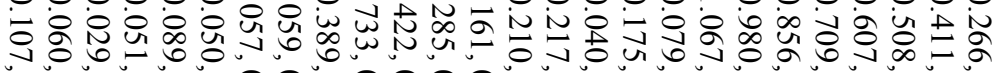

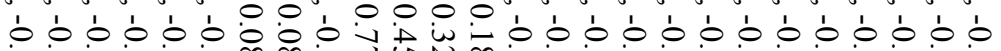

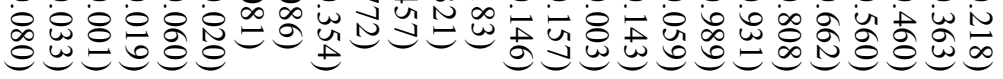

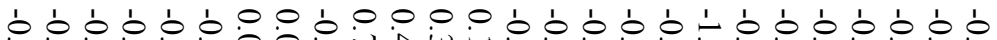

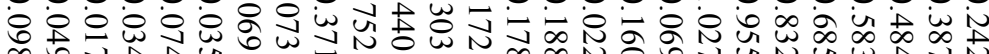
* $*$ * $*$ * $*$ * $*$ *

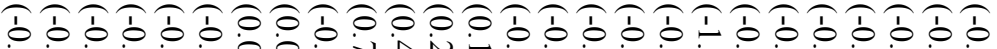

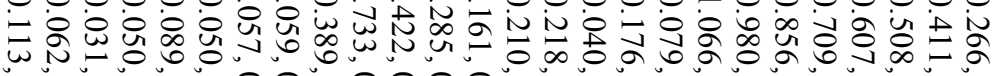

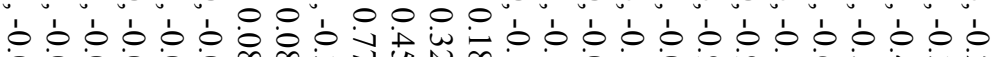

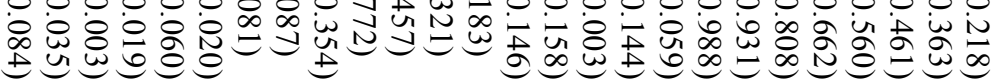

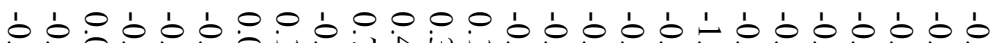

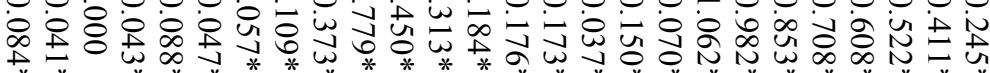

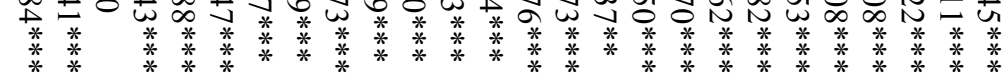

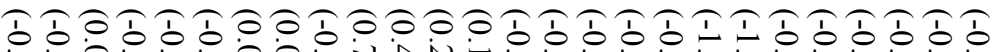

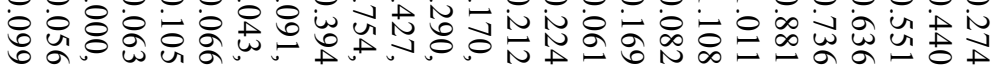

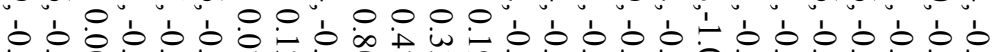

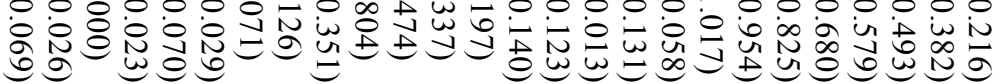

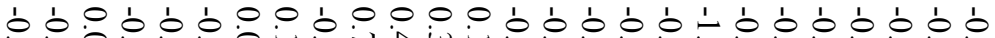

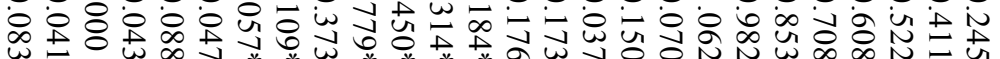

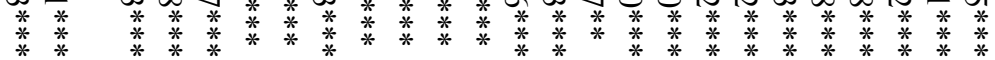

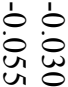

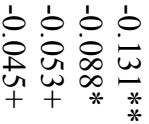

.0 .0

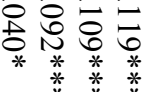

อิวิอิอ

$8 \dot{8} \dot{8} \dot{0}$ 0000

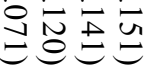

000.0

$\dot{\omega} \dot{\bar{L}} \dot{\bar{\omega}}$

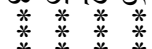

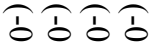
$\dot{8} \overline{\mathrm{\omega}} \dot{\mathrm{a}} \mathrm{N}$

$\circ \circ$ o 1

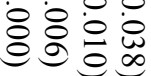

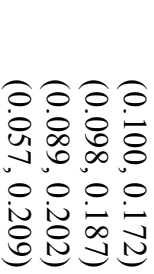

$\begin{array}{ll}0 & 0 \\ 0 & : \\ 0 & 0 \\ * & 0 \\ * & * \\ * & *\end{array}$

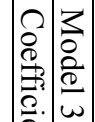

อิอ

岕

这㥕

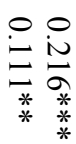

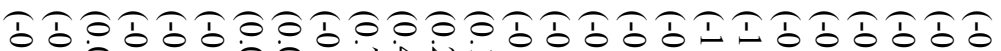

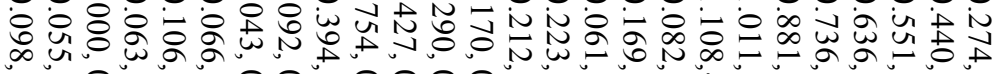

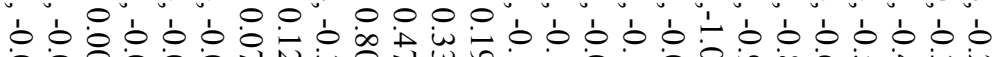

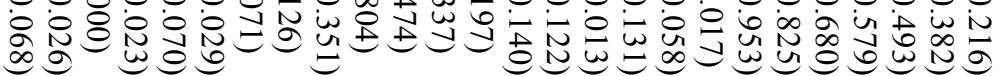

I)

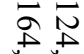
0.0 ํํㅇ 


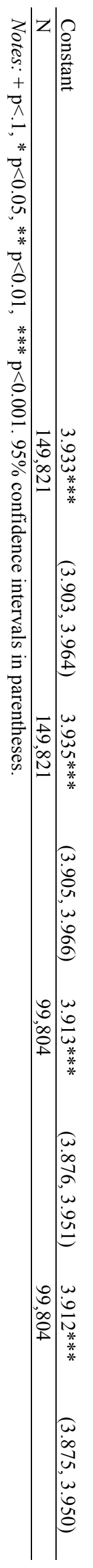




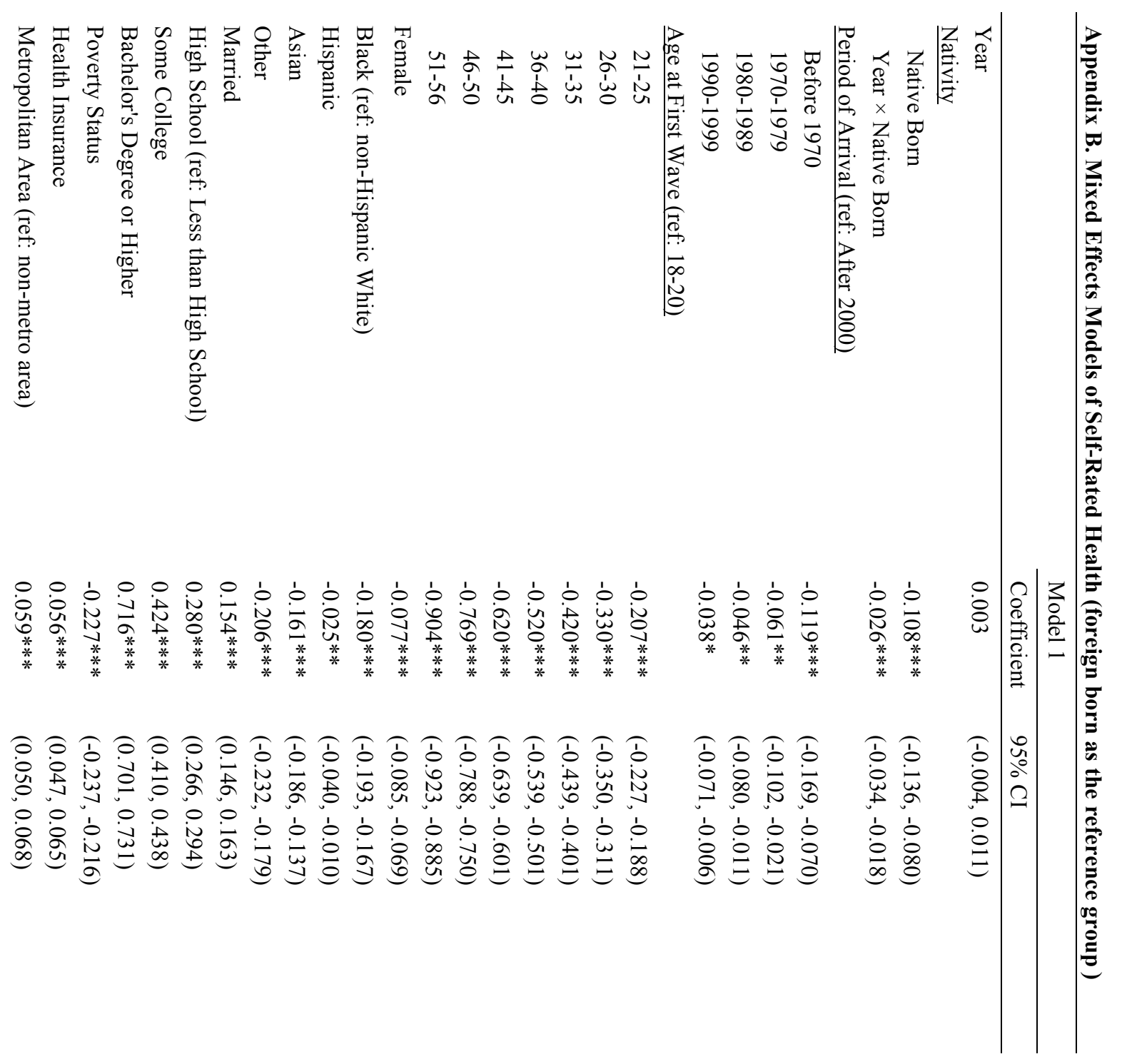




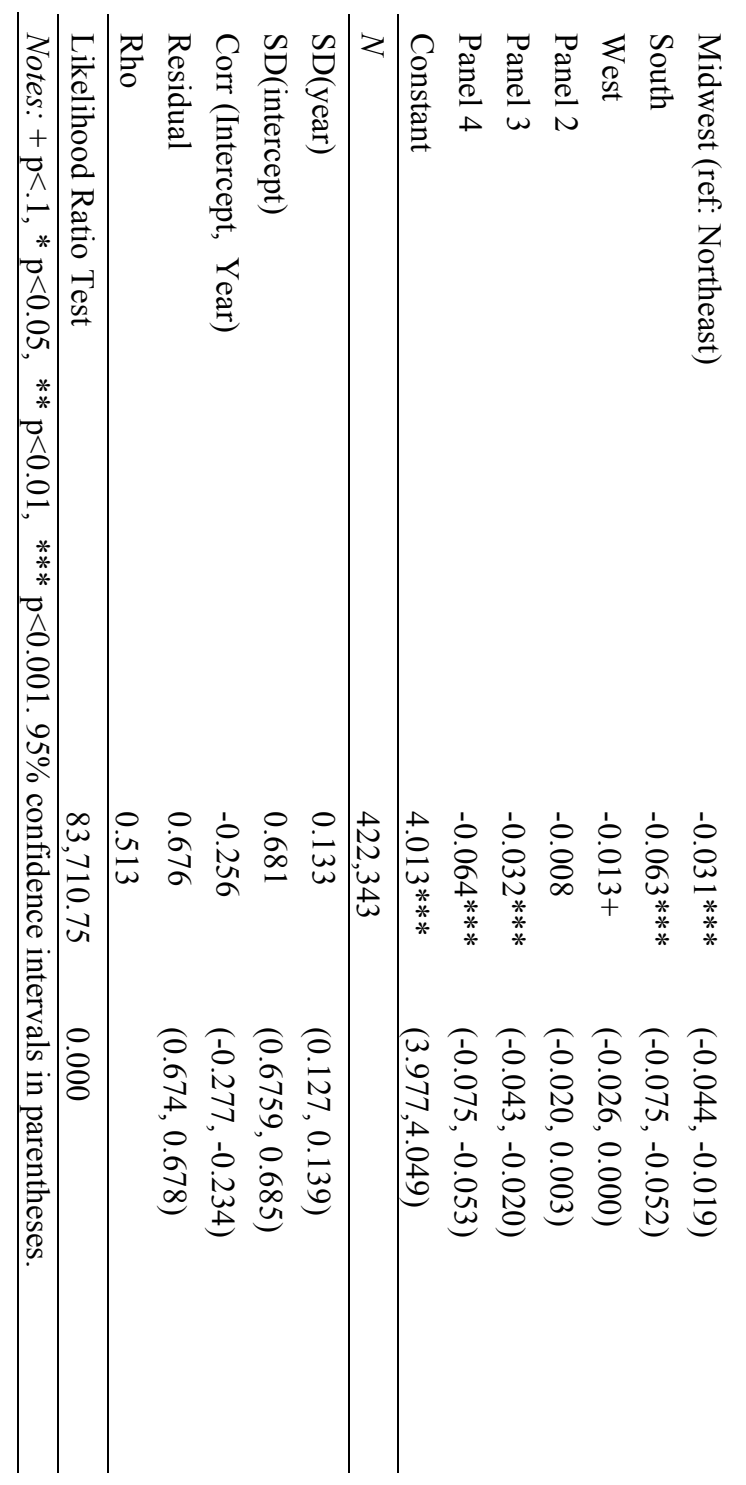




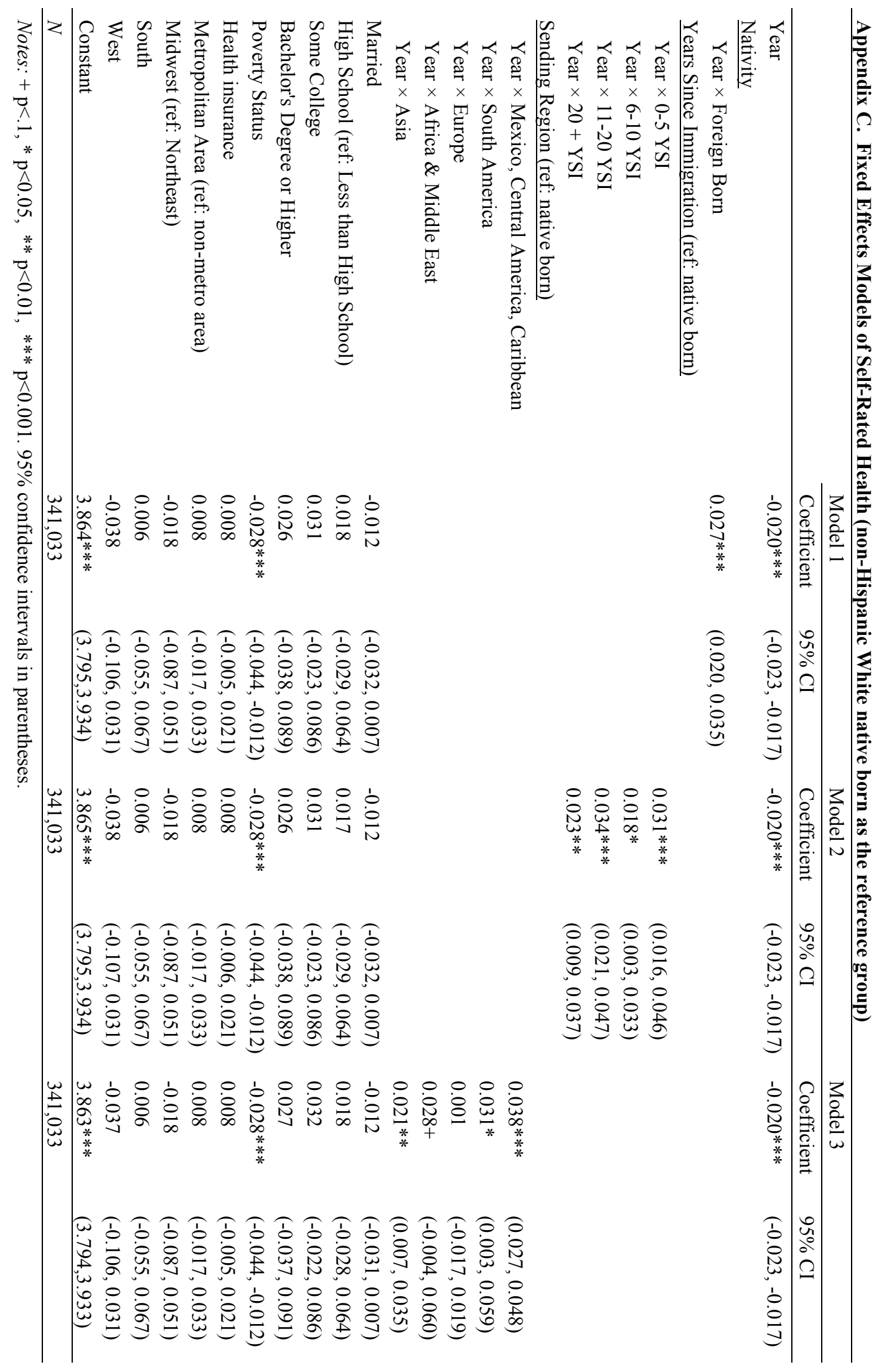




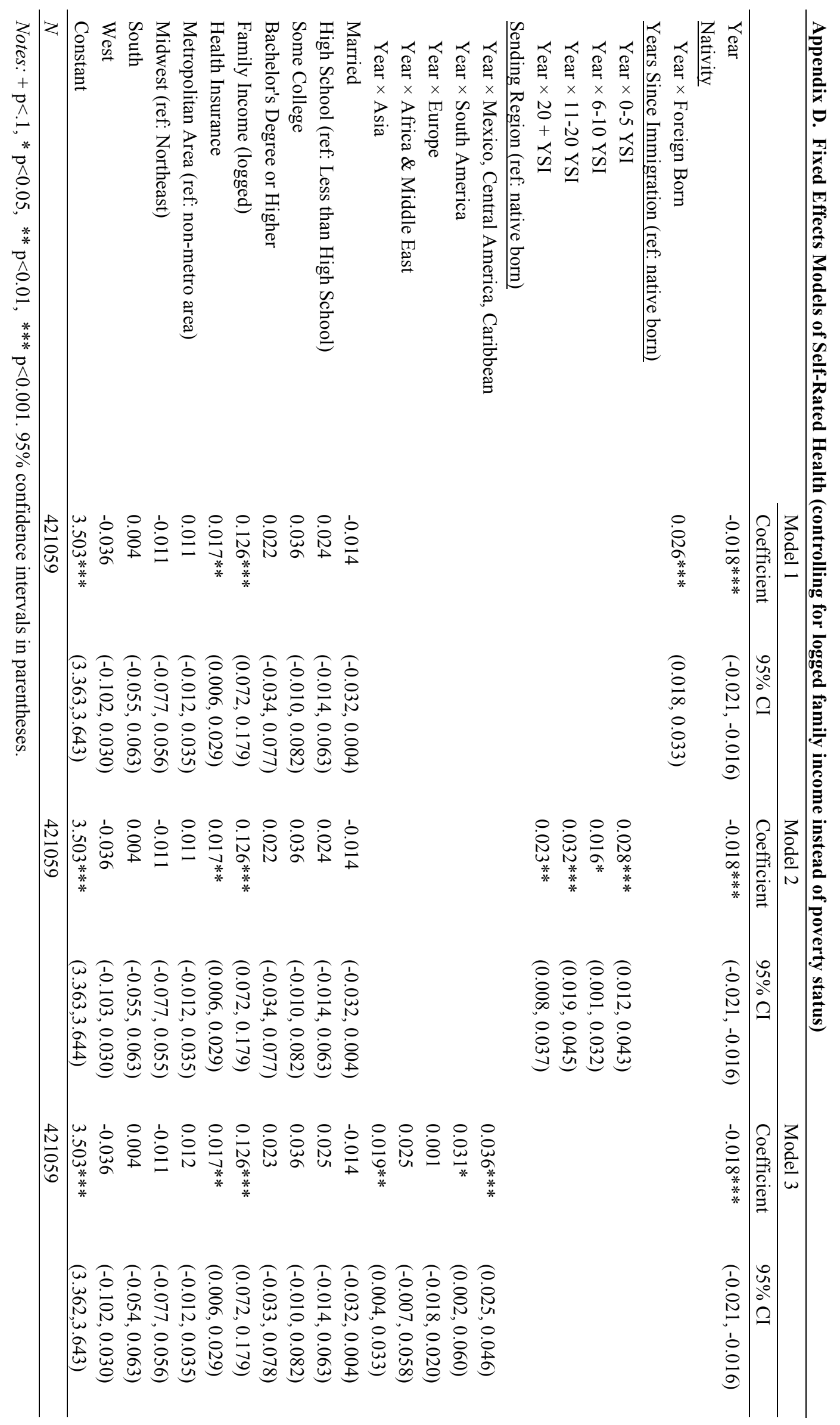




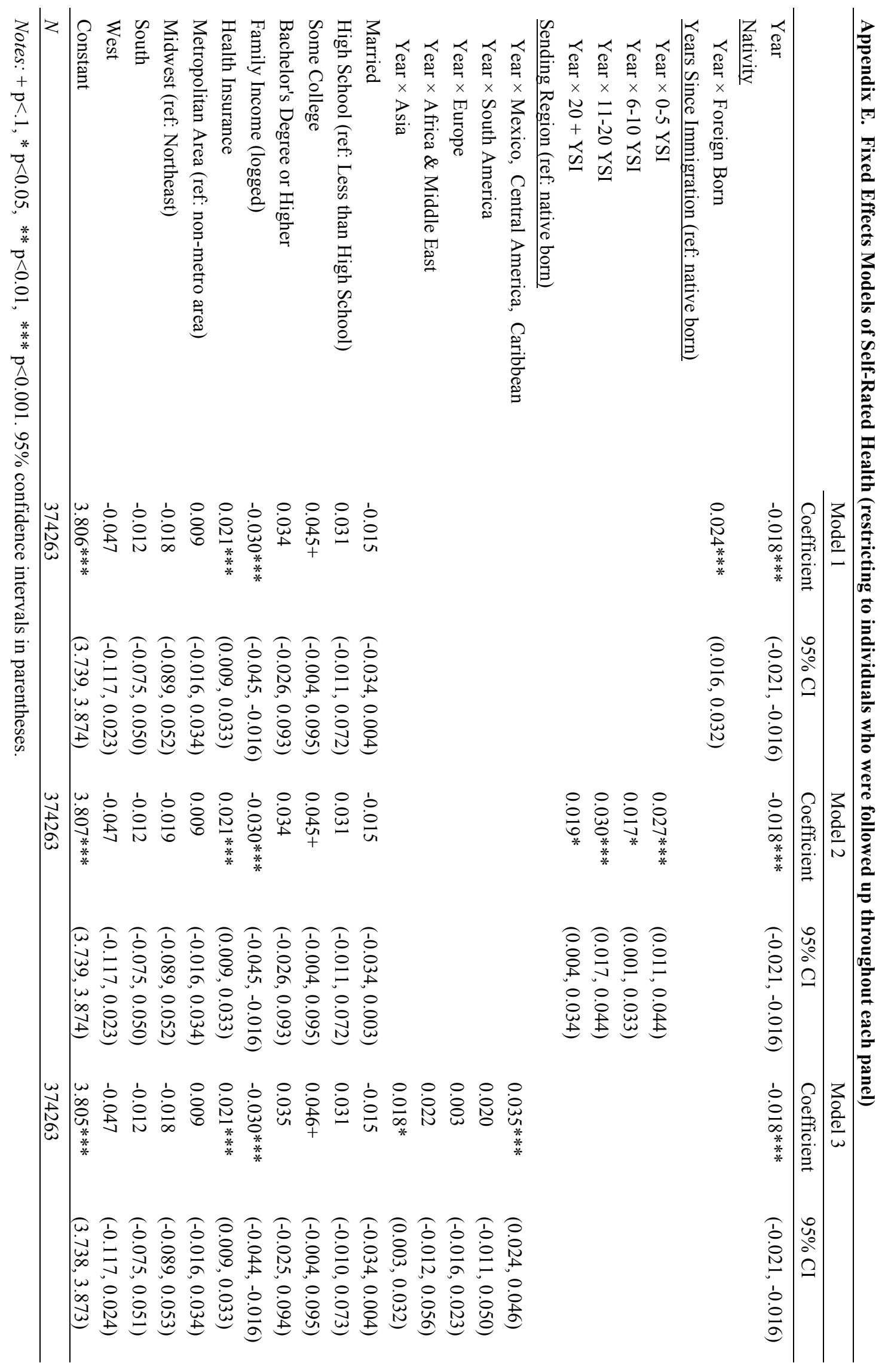

